\title{
Notch Signaling Slows Down the Progression of Embryonic Myogenic Differentiation in Landrace
}

\section{Shufang Cai}

Sun Yat-sen University School of Life Science

Qi Zhu

Sun Yat-sen University School of Life Science

\section{Bin $\mathrm{Hu}$}

Guangdong Academy of Agricultural Sciences

Xiaorong Luo

Sun Yat-sen University School of Life Science

\section{Renqiang Yuan}

Sun Yat-sen University School of Life Science

Feng Liang

Sun Yat-sen University School of Life Science

Tianqi Duo

Sun Yat-sen University School of Life Science

Keren Chen

Sun Yat-sen University School of Life Science

\section{Yaosheng Chen}

Sun Yat-sen University School of Life Science

Delin Mo ( $\square$ modelin@mail.sysu.edu.cn )

Sun Yat-Sen University https://orcid.org/0000-0002-8738-4486

\section{Research}

Keywords: porcine embryonic myogenesis, myogenic progenitors, Notch signaling, Pax7, MyoD

Posted Date: November 12th, 2020

DOI: https://doi.org/10.21203/rs.3.rs-104072/v1

License: (a) (1) This work is licensed under a Creative Commons Attribution 4.0 International License. Read Full License 


\section{Abstract}

\section{Background}

Delving into porcine embryonic myogenesis is the key to elucidating the complex regulation of breedspecific differences in growth performance and meat production. Increasing evidence proved that pigs with less meat production showed more intense embryonic myogenesis, but little is known about the underlying mechanisms.

Results

In this study, we confirmed that the differentiation process of myogenic progenitors in Lantang pig (LT, fat) was faster than that in Landrace pig (LR, lean), which resulted in more differentiated myoblasts $\left(\mathrm{Pax} 7^{-} / \mathrm{MyoD}^{+}\right.$) but less myogenic progenitors ( $\left.\mathrm{Pax} 7^{+} / \mathrm{MyoD}^{-}\right)$in $\mathrm{LT}$ at 35 days post-conception (35dpc). Additionally, in vitro, embryonic myogenic progenitors isolated from LT showed stronger differentiation capacity with earlier expression of MyoD. Furthermore, the expression levels of genes related to Notch signaling in LR progenitor cells were significantly higher than that of $L T$, while there was no significant difference between the two breeds in gene expression levels of Wnt and Akt/mTOR pathway. Inhibition of Notch signaling or knockdown of Pax7 promotes myogenic differentiation of primary progenitor cells or myoblasts, while activation of Notch signaling or overexpression of Pax7 has the opposite effects.

\section{Conclusions}

Myogenic differentiation is more rapid in LT than that in LR at 35dpc. Mechanically, Notch signaling facilitates maintenance of myogenic progenitor cells and antagonizes myogenic differentiation by promoting Pax7 expression but preventing MyoD expression in LR.

\section{Background}

Porcine skeletal muscle growth is predominantly determined by the total number of myofibers formed during prenatal skeletal muscle development, including two successive generations of myofibers [1, 2]. Primary (embryonic) myogenesis takes place between 35 and 55 days post-conception (dpc), forming the first appeared multinucleated muscle fibers, which are officially called as primary myofibers and establish the scaffold of skeletal muscles. Following this, secondary (fetal) myofibers form around each primary myofiber from 50 until $90 \mathrm{dpc}$, and are important for muscle growth and maturation [3, 4]. The number and size of primary myofibers have a positive correlation with the number of secondary myofibers and the total number of myofibers. Thus, delving into porcine embryonic myogenesis is the key to elucidating the complex regulation of breed-specific differences in growth performance and meat production.

Myogenic progenitors, originated from cells of the dermomyotome, labeled by the paired box transcription factors Pax3 and Pax7, are responsible for muscle development [5]. During embryonic muscle formation, a fraction of muscle progenitors, referred as embryonic progenitors, proliferate, differentiate and fuse into 
myotubes. This progress is under the cooperative control of the muscle regulatory factors (MRFs) Myf5, MyoD, Myogenin (MyoG), and MRF4 [6]. Among them, Myf5 and MyoD, as myogenic commitment factors, contribute to myoblast specification and differentiation, while MyoG and MRF4 are differentiation factors, inducing myogenic terminal differentiation $[7,8]$.

Molecular mechanisms concerning determination and differentiation of myoblasts during porcine embryonic development remain to be further explored. Studies in mouse have reported that Notch and Wnt signaling pathways are involved in this process. Notch signaling pathway is implicated as an important regulator of proliferation and differentiation of myogenic progenitor cells $[9,10]$. In addition, it is also very important in maintaining satellite cells quiescence $[11,12]$. Notch signaling activation requires physical interaction between a ligand (delta1/4 or jagged 1/2) and one of the four Notch receptors (notch 1-4). This interaction leads to the release of the Notch intracellular domain (NICD) which then translocates into nucleus where it binds to the Rbpj transcription factor and induce downstream effectors, such as the Hes/Hey family $[13,14]$. Wnt signaling has been demonstrated to be crucial for the maintenance of fetal muscle progenitors in mouse $[15,16]$, and also has been proved to play a great role in the expansion of satellite cells $[16,17]$. In addition, AKT/mTOR signaling also regulates the differentiation of myoblasts [18].

Increasing evidence proved that pigs with less meat production showed more intense embryonic myogenesis. For example, the myofiber density and diameter were significantly higher in Meishan pigs (fatty, a Chinese indigenous breed) compared to Large White pigs (a lean breed) at 35dpc [19]. In our previous study, we found that Wuzhishan pigs (fatty) showed earlier myoblast differentiation than that of Landrace pigs (LR, lean) in embryonic stages [20]. Primary muscle fibers appear earlier in Lantang (LT, fatty) than that in LR, at $35 \mathrm{dpc}$ and $42 \mathrm{dpc}$ respectively [21]. These observations suggest that the progression of embryonic myogenic differentiation is faster in obese pig breeds, which result in precocious myofiber formation. To verify this possibility, in the present study, we compared the dorsal myogenesis progression of LT and LR pigs at $35 \mathrm{dpc}$, as well as the differentiation capacity of their myogenic progenitors in vitro. Further, for the first time, the molecular mechanism concerning their differences was linked to Notch signaling.

\section{Results}

\section{Myogenesis progression is more intense in LT than that in LR at 35dpc}

To study early embryonic myogenesis, the expression of embryonic myosin heavy chain (eMyHC, a marker for fully differentiated myocytes) was analyzed in longissimus dorsi muscle (LDM) of LT and LR pigs at $35 \mathrm{dpc}$. There were more eMyHC ${ }^{+}$cells in LT (Fig. 1a and b), which is consistent with previous reports, indicating precocious terminal differentiation of myoblasts in LT [20]. To define the progression of myogenic differentiation, dual immunostaining of Pax7 and MyoD was conducted. As a result, the percents of committed myoblasts $\left(\mathrm{Pax}^{+} / \mathrm{MyoD}^{+}\right)$and differentiated myoblasts $\left(\mathrm{Pax} 7^{-} / \mathrm{MyoD}^{+}\right)$were both higher in LT (Fig. 1c and d). The percent of undifferentiated progenitors ( $\left.\mathrm{Pax} 7^{+} / \mathrm{MyoD}\right)$ was higher in $\mathrm{LR}$. 
Accordingly, higher level of Pax7 protein and lower level of MyoD protein were found in LR (Fig. 1e). Altogether, these results demonstrate that myogenesis process is more intense in LT than that in LR at $35 \mathrm{dpc}$, which is well explained by the stronger myogenic differentiation tendency of muscle progenitors in LT.

\section{Embryonic muscle progenitors from LT express MyoD earlier and have stronger differentiation capacity in vitro}

To further investigate myogenic potentials of embryonic muscle progenitors in these two pig breeds, we isolated them from LDM by collagenase digestion combined with differential adherent purification. Identification of isolated cells by immunofluorescence staining showed that the Pax7-positive cells and Desmin-positive cells accounted for more than $80 \%$ of total cells respectively, both for LT and LR (Fig. 2a, $\mathrm{b}$ and $\mathrm{c}$ ). In vivo study proved that muscle progenitors in LT showed a stronger myogenic differentiation tendency, we supposed that MyoD expression in LR progenitors may be slowed down, which subsequently blocked myogenic differentiation. To test this hypothesis, newly isolated LT and LR progenitors were cultured in growth medium, and time course expression of MyoD was tested by immunofluorescence staining (Fig. 2d). With the extension of culture time, MyoD ${ }^{+}$cell numbers gradually increased both in LT and LR progenitors. Compared with LR, more MyoD ${ }^{+}$cells appeared earlier in LT progenitors (Fig. 2e). Then, immunofluorescence staining for eMyHC was performed to compare the differentiation ability of two kinds of progenitors at day 6 after differentiation. Significantly, $\mathrm{eMyHC}^{+}$ myotubes generated from LT progenitors were more and larger than that from LR progenitors (Fig. 2f). The statistical results indicated that LT progenitor showed a higher fusion index than LR progenitors (Fig. $2 \mathrm{~g}$ ). Congruent with these findings, protein levels of MyoD and MyoG were higher in LT progenitors (Fig. $2 \mathrm{~h}$ ). Collectively, these results indicate that embryonic muscle progenitors from LT showed earlier expression of MyoD, and have stronger differentiation capacity in vitro.

\section{Notch signaling is more active in LR myogenic progenitors}

To explore the molecular mechanism of different differentiation property between LT and LR progenitors, we detected Wnt, AKT/mTOR and Notch signaling pathways. The expression of total protein level and active protein level of $\beta$-catenin, an important mediator of canonical Wnt signaling pathway, were comparable between LT and LR progenitors (Fig. 3a). To examine the activity of the AKT/mTOR pathway, the expression levels of total and phosphorylated protein of AKT and S6K1 were measured. Results revealed that the levels of AKT, pAKT, S6K1 and pS6K1 showed no difference between two breeds (Fig. 3b and c). Interestingly, qPCR results revealed that Notch genes, including ligand (Jagged1), Notch receptors (Notch1 and Notch3), Rbpj transcription factor (Rbpj) and downstream effectors (Hey1, HeyL and Hes1) had higher mRNA levels in LR progenitors (Fig. 3d). In line with these results, Western blotting demonstrated the protein levels of Jagged1, Hey1 and Hes1 were higher in LR (Fig. 3e). Immunofluorescence staining proved that there were more Jagged1 protein expressed in LR dorsal cells, whether it is a Pax7 $7^{+}$cell or a Pax7 ${ }^{-}$cell (Fig. 3f). Collectively, Notch signaling was more active in LR myogenic cells. 


\section{Boosted Notch signaling prevents $\mathrm{C} 2 \mathrm{C} 12$ myoblast differentiation}

To further clarify the regulatory function of Notch signaling on myogenic differentiation, $\mathrm{C} 2 \mathrm{C} 12$ cells were treated with the peptide of Jagged1, a Notch ligand known to activate Notch signaling in skeletal muscle cells. After 2 days of Jagged1 treatment in GM, the expression of Pax7 was up-regulated while MyoD was down-regulated (Fig. 4a). In addition, the percentages of $\mathrm{Pax}^{+} / \mathrm{MyoD}^{+}$and $\mathrm{Pax} 7^{-} / \mathrm{MyoD}^{+}$cells were decreased, and the percentage of $\mathrm{Pax}^{+} / \mathrm{MyoD}^{-}$cells was increased (Fig. $4 \mathrm{~b}$ and c), which implied that Notch signaling prevents myogenic differentiation. Then, $\mathrm{C} 2 \mathrm{C} 12$ cells were induced to differentiate in DM supplemented with Jagged1 peptide, followed by differentiation assays. As a result, the percentage of MyoG $^{+}$cells was significantly reduced after 1 day treatment (Fig. $4 \mathrm{~d}$ and e). When induced to differentiate for 3 days, as expected, cells treated with jagged 1 formed less myotubes (Fig. 4f), which was proved by a decreased fusion index (Fig. 4g). In line with this, the expression of MyoG and MHC were down-regulated, indicating there is a differentiation defect in Jagged1 treated myoblasts (Fig. 4h).

\section{Inhibition of Notch signaling promotes the differentiation of embryonic myogenic progenitors in vitro}

Given that Notch signaling was over-activated in LR progenitors and it has inhibitory effect on myoblast differentiation, we speculated that this signaling contributes to the difference of differentiation ability between two kinds of muscle progenitors. LR progenitors were cultured in growth medium containing 20 $\mu \mathrm{M}$ y-secretase inhibitor DAPT囚an inhibitor of Notch signaling $\$ to inhibit Notch activity. As expected, the expressions of Notch effectors Hey1, HeyL and Hes1 were decreased after DAPT treatment (Fig. 5a and b). In addition, inhibition of Notch signaling led to down-regulated Pax7 expression and up-regulated MyoD expression (Fig. 5c and d). Furthermore, time course expression of MyoD was tested by immunofluorescence staining. As a result, there were more MyoD ${ }^{+}$cells in the DAPT group at each indicated time (Fig. 5e and f). Immunofluorescence staining and Western blotting for eMyHC at day 6 after differentiation revealed a lower cell fusion index together with a decreased eMyHC protein level in DAPT-treated groups (Fig. $5 \mathrm{~g}$, h and i). Taken together, these findings indicate that Notch inhibition prevents Pax7 but promotes MyoD expression as well as myogenic differentiation.

\section{Pax7 inhibits terminal differentiation of myoblasts}

The above assays have proved that Notch signaling promotes the expression of Pax7. Then, in order to verify that the regulatory effect of Notch signaling on myogenic differentiation is mediated through Pax7, we explored the specific influences of Pax7 on myoblasts differentiation. $\mathrm{C} 2 \mathrm{C} 12$ cells were transfected with Pax7 siRNAs to knock down Pax7 expression. As a result, MyoD level was not changed, but Myf5 level was down-regulated (Fig. 6a and b). Although Pax7 knockdown resulted in loss of Myf5 expression in $\mathrm{C} 2 \mathrm{C} 12$ cells cultured in a low-density, it promoted MyoG expression in cells differentiated for 1day (Fig. $6 \mathrm{c}$ and d). Accordingly, Pax7 knockdown cells formed more $\mathrm{MyHC}^{+}$myotubes with increased fusion index after 3 days differentiation (Fig. 6e and f), and showed up-regulated protein levels of MyoG and MyHC (Fig. 6g). To further confirm the function of Pax7, Pax7 expression vector was transfected into $\mathrm{C} 2 \mathrm{C} 12$ cells. As a result, the mRNA and protein levels of Myf5 were partially increased (Fig. 6h and i). 
Immunofluorescence assay showed that over expression of $P a x 7$ in $\mathrm{C} 2 \mathrm{C} 12$ cells reduced the percentage of cells expressing MyoG at differentiation 1 day (Fig. 6j and k), and MyHC expression was inhibited, which resulted in a decrease of fusion index at differentiation 3 day (Fig. 6l, $m$ and $n$ ). These observations proved that Pax7 inhibits terminal differentiation of myoblasts.

\section{Notch signaling slows down myogenic differentiation of muscle progenitors in embryo limbs}

In order to verify the correlation between earlier progression of myogenic differentiation and repressed Notch signaling in LT with less muscle, an ex vivo limb culture system was employed [22, 23]. Embryo forelimbs were separated at $35 \mathrm{dpc}$ and cultured for 30 hours, with or without $20 \mu \mathrm{M}$ DAPT. qPCR analysis showed that Notch genes were successfully suppressed after DAPT treatment (Fig. 7a and c). In addition, inhibition of Notch signaling led to reduced numbers of $\mathrm{Pax}^{+} / \mathrm{MyoD}^{-}$cells, whereas the $\mathrm{MyoD}^{+}$cell population was increased (Fig. 7d and e), confirming the robustness of our ex vivo model. Accordingly, we found decreased expression level of Pax 7 and increased level of MyoD in DAPT-treated samples (Fig. 7b and c). Altogether, these results demonstrate that in embryonic muscle progenitor cells Notch signaling antagonizes myogenic differentiation by promoting Pax7 expression and preventing MyoD expression.

\section{Materials And Methods}

\section{Experimental animals and tissues}

Six LT sows and six LR sows were artificially inseminated with semen from the same breed boars, respectively. All sows were slaughtered at $35 \mathrm{dpc}$ after insemination, and embryos were collected as previously described. For each embryo, the longissimus dorsi muscle (LDM) tissues were isolated, then, digested to isolate embryonic muscle progenitors or fixed to prepare paraffin sections of tissue, or frozen in liquid nitrogen for further use.

\section{Embryonic muscle progenitors isolation and culture condition}

Embryonic muscle progenitors were isolated from the LDM of embryos of two breeds at $35 \mathrm{dpc}$. The isolated LDM was cleaned free of connective tissues, minced and digested with $0.2 \%$ Collagenase type I (Sigma, Shanghai, China) solution at $37^{\circ} \mathrm{C}$ water bath for $2 \mathrm{~h}$ to get sufficient cells. Mixed cells was preplated $2 \mathrm{~h}$ in $5.0 \mathrm{ml}$ growth media on a culture dish to remove fibroblasts and then transferred to a new culture dish for attachment. Cells were cultured in Dulbecco's modified Eagle medium (DMEM) supplemented with $20 \%(\mathrm{v} / \mathrm{v}$ ) fetal bovine serum (FBS), $1 \%$ penicillin-streptomycin antibiotics and $0.5 \%$ chicken essential extract (growth medium, GM). For experiments, muscle progenitors were sub-cultured onto 12-well plates at densities of $1.0 \times 10^{4}$ cells per well. Cells were switched into DMEM with $2 \%$ horse serum (differentiation medium, DM) after reaching $100 \%$ confluence to induce differentiation.

C2C12 cells were purchased from American Tissue Culture Collection (CATCC), cultured in DMEM with $10 \%$ FBS, and 1\% penicillin-streptomycin (growth medium, GM) at subconfluent density. To induce 
differentiation, cells were switched into DM after reaching 100\% confluence. All cells were cultured at 37 ${ }^{\circ} \mathrm{C}$ in a humidified atmosphere of $5 \% \mathrm{CO}_{2}$.

\section{In vitro Notch activation or inhibition}

For Notch activation, C2C12 cells were treated with the Jagged1 peptide (CDDYYYGFGCNKFCRPR) or a control scrambled peptide (RCGPDCFDNYGRYKYCF) (GenScript USA, Inc.) $(20 \mu \mathrm{g} / \mathrm{ml})$ for 48 or $72 \mathrm{~h}$ in proliferation or myogenic differentiation assay $[24,25]$. For Notch inhibition, embryonic muscle progenitors cultured in GM were treated with DAPT (N-[N-(3,5-difluorophenacetyl)-L-alanyl]-Sphenylglycine t-butyl ester) ( $20 \mu \mathrm{M}$, solved in DMSO) for $60,72,84,96,108,120$ or $132 \mathrm{~h}$ according to different assays; embryonic muscle progenitors cultured in DM were treated with DAPT for $144 \mathrm{~h}$; control cells were treated with carrier (DMSO) only [26].

\section{siRNAs, plasmids and transfection}

For RNA interference, negative control siRNAs (siNC) and three stealth mouse Pax7 siRNAs were purchased from Invitrogen (Thermo Fisher Scientific, USA) (Table. S1). siPax7-2 was the most efficient (Fig. S1). So, it was used in all of the following analysis. For Pax7 expression vector, mouse Pax7 CDS sequence was inserted into pcDNA3.1 vector (Invitrogen, Shanghai, China). C2C12 cells were transfected with siRNAs or plasmids using Lipofectamine 3000 (Invitrogen) according to the manufacturer's instruction. All transfections were performed in triplicate for each experiment.

\section{Explant}

Forelimbs from LR 35 dpc embryos were cultured in 12-well plates in BGJb medium (Life Technologies), without FBS, with $200 \mu \mathrm{g} / \mathrm{ml}$ ascorbic acid (Life Technologies) and 1\% penicillin-streptomycin antibiotics. For Notch inhibition, forelimbs originating from the same embryo were immediately treated with $20 \mu \mathrm{M}$ DAPT or DMSO carrier for $30 \mathrm{~h}$. Then, treated and control forelimbs were cleaned and collected for further analysis.

\section{Western blot}

Protein extracts were obtained from incubating cultured cells, LDM or forelimbs homogenates in lysis buffer $(150 \mathrm{mmol} / \mathrm{L} \mathrm{NaCl}, 50 \mathrm{mmol} / \mathrm{L}$ Tris, $1 \%$ Triton X-100, 1\% sodium deoxycholate, $0.1 \%$ SDS, pH 8.0) supplemented with protease inhibitor phenylmethanesulfonyl fluoride (PMSF, Thermo Scientific) on ice until protein was released completely. Total extracts were separated by SDS-PAGE on 10\% (w/v) polyacrylamide gels, transferred onto $0.45 \mu \mathrm{m}$ PVDF membrane (Roche). After being blocked in $4 \%$ bovine serum albumin (BSA) for 1-2 $\mathrm{h}$, the membranes were incubated with specific primary antibodies at $4{ }^{\circ} \mathrm{C}$ overnight, then incubated with secondary antibodies for $1 \mathrm{~h}$ at room temperature. Blots were visualized using an enhanced chemiluminescence (ECL) detection kit (FDbio, Hangzhou, China). $\beta$ Tubulin and GAPDH were used as internal controls. Antibodies are listed in Table S2. 
Total RNA was extracted from cultured cells, LDM or forelimbs according to the instructions of TRIzol® Reagent (Invitrogen, Shanghai, China), then cDNA was synthesized from $1 \mu \mathrm{g}$ total RNA using a reversetranscription Kit (Promega, Beijing, China). The real-time quantitative PCR (qPCR) was performed using a SYBR Green qPCR Kit (Genestar, Beijing, China), detected on the LightCycler 480 II system (Roche, Basel, Switzerland). The primers used for qPCR were given in Table S3. Gapdh was used as internal control and all reactions were run in triplicate.

\section{Immunofluorescence}

Cultured cells were fixed in $4 \%$ paraformaldehyde for 10 minutes, permeabilized in $0.5 \%$ Triton X-100 for 15-20 minutes. After being blocked with 4\% BSA in Tris-buffered saline with Tween (TBST) for 1 hour, the cells were incubated with primary antibodies overnight at $4^{\circ} \mathrm{C}$, followed by incubation with secondary antibodies for 1 hour at room temperature. The nuclei were counterstained with 4',6-diamidino-2phenylindole (DAPI; 1:1000 in PBS). Antibodies are listed in Table S2. Immunostaining images were obtained via fluorescent reverse microscopy (Nikon, Tokyo, Japan).

\section{Immunohistochemistry}

LDM or forelimbs were fixed in $4 \%$ paraformaldehyde for $19 \mathrm{~h}$ at $4^{\circ} \mathrm{C}$, then dehydrated using gradient alcohol and embedded with paraffin. Paraffin embedded samples were cut into $5-\mu \mathrm{m}$ sections. The paraffin sections were placed in an oven at $64^{\circ} \mathrm{C}$ for 30 minutes and immediately moved to xylene for dewaxing. Rehydrated in gradient alcohol, antigen repaired using citrate antigen retrieval solution. Finally, immunofluorescence was performed using IHC Kit (Abcam, Cambridge, England) according to the manufacturer's instruction. Immunostaining images were obtained via fluorescent reverse microscopy (Nikon).

\section{Statistical test}

Immunostainings were performed on at least three embryos of each group. Images of immunostainings were randomly selected for analysis. The fusion index was calculated as the percentage of nuclei in fused myotubes out of the total nuclei. Data are presented as mean \pm sem or mean from at least three independent experiments. Statistical differences between groups were tested using an unpaired twotailed Student's t-test. Values of $\mathrm{P}<0.05$ was considered as significance.

\section{Discussion}

Different pig breeds vary in muscle mass because of differences in muscle development. In recent years, several studies revealed that pigs with less muscle showed earlier formation of primary myofibers, which arise from earlier expression of myogenic genes [20]. In the present report, we found more eMyHC-positive cells in LT LDM at $35 \mathrm{dpc}$, indicating precocious terminal differentiation of myoblasts in LT. MyoD, which can initiate the process of multiple non-muscle cell lineages into muscle cell lineages, is a crucial master switch in regulating muscle-specific gene transcription $[27,28]$. Its higher expression in LT reflected that 
dermomyotome-derived muscle progenitors differentiated more rapidly, leading to a larger percentage of differentiating myoblasts and differentiated myocytes in LT. Consistently, in vitro experiments, the MyoDpositive cells appeared earlier in LT progenitors, resulting in more eMyHC-positive myotubers with a higher fusion index. Collectively, these analyses suggested that LT muscle progenitors showed a stronger myogenic differentiation tendency in early embryonic stage which is relevant to earlier and higher MyoD expression.

Signals mediated by the Notch pathway is involved in the regulation of myogenic differentiation in vertebrate embryos and cultured cell lines [26, 29, 30]. Activation of Notch signaling in C2C12 myoblasts can repress MRFs as well as other muscle-specific genes expression, and block myotube formation [31, 32, 33]. In mouse embryos, the Notch ligand Delta1 (DII1) controls both maintenance of myogenic progenitors and early differentiation of myoblasts [34]. In Xenopus embryos, MyoD regulates expression of DII1, suggesting a feedback loop between Notch signaling and myogenic basic helix-loop-helix proteins during vertebrate myogenesis and a potential role of Notch in myogenic determination [35]. However, overexpression of DIl1 in chick embryos did not affect early steps of myogenesis, but it blocked the differentiation of postmitotic myogenic cells [29]; and Notch in zebrafish embryos controls the segmental arrangement of myogenic cells, but it does not affect their commitment or differentiation [36, $37,38,39]$. Taken together, Notch signaling plays varying roles during embryonic myogenesis in different vertebrate species. In this study, the higher expression levels of Notch genes in LT LDM suggesting it may function in porcine skeletal muscle development and contributes to the differences in embryonic myogenesis between pig breeds. Then, using in vitro Notch manipulation and an ex vivo limb culture system, we found that Notch signaling facilitates maintenance of myogenic progenitor cells and antagonizes myogenic differentiation by promoting Pax7 expression but preventing MyoD expression.

The precise influence of $\mathrm{Pax} 7$ on myogenic progression remains a controversial debate. $\mathrm{Pax} 7 /^{-}$mice have no evident defects in muscle formation [40]. However, it shows a progressive loss of satellite cells in multiple muscle groups [41]. In adult muscle, quiescent satellite cells show a high expression of Pax7, whereas Myf5 and MyoD is almost nondetectable [42]. Once activated, Pax7 protein persists at lower levels in proliferating satellite cells and decreases rapidly in cells that commit to terminal differentiation [43]. In cultures, Pax7 is not detectable in differentiated myotubes, but persists in undifferentiated and mitotically inactive myogenic cells that reduce MyoD expression [44]. Moreover, ectopic expression of Pax7 represses the MyoD-dependent conversion of mesenchymal cells to myoblasts [45]. However, plated satellite cell-derived myoblasts exhibit an increase in the number of cells containing MyoD in the presence of constitutive Pax7 [46]. Primary myoblasts where Pax7 was deleted exhibited a reduction in the levels of Myf5 and MyoD expression, and no change in myogenin expression [47]. Here, when myoblasts were cultured at a low-density in GM, the expression of Myf5 but bot MyoD was positively influenced by Pax7. When cultured at a high-density in DM, Pax7 knockdown cells up-regulated MyoG expression and cells differentiated precociously. On the contrary, overexpression of Pax7 hindered myogenic differentiation by repressing MyoG expression. These results demonstrate that Pax 7 inhibits 
precocious terminal differentiation, suggesting that pressed Pax7 expression resulted from weaker Notch signals contributes to intense myogenic differentiation progression in LT progenitors.

Embryonic and fetal muscle development depends on a sufficient population of myogenic progenitors that are characterized by expression of the paired-box transcription factors Pax3 and Pax7 [48, 49]. By dual immunostaining of Pax7 and MyoD, we confirmed that the myogenic differentiation progression in LT embryos was more rapidly than that in LR embryos, which resulted in more differentiated myocytes (eMyHC+) at $35 \mathrm{dpc}$ but a serious depletion of progenitor cells ( $\left.\mathrm{Pax}^{+} / \mathrm{MyoD}^{-}\right)$. Previous study has reported that premature myogenic differentiation and depletion of progenitor cells cause severe muscle hypotrophy [9]. We speculated that the severe loss of muscle progenitors caused by intense myogenesis at early embryonic stage should be one of the reasons for the less meat production of LT pigs, for there are not sufficient progenitors differentiating into muscle fibers in the later stage of embryo, resulting in a small total number of muscle fibers.

\section{Conclusion}

In summary, we show here that myogenic differentiation is more rapidly in LT than that in LR at $35 \mathrm{dpc}$. In addition, embryonic muscle progenitors from LT have stronger differentiation capacity in vitro.

Mechanically, as shown in Fig. 8, the stronger Notch signaling in LR myogenic progenitors facilitates the maintenance of myogenic progenitor cells and antagonizes myogenic differentiation by promoting Pax 7 expression but preventing MyoD expression. The results presented here may provide new insight into studying the mechanisms of difference in meat production between different pig breeds.

\section{Abbreviations}

LT: Lantang pig; LR: Landrace pig; pdc: post-conception; MRFs: the muscle regulatory factors; eMyHC: embryonic myosin heavy chain; LDM: longissimus dorsi muscle; si-Pax7: Pax7 siRNAs; DMEM:

Dulbecco's modified Eagle medium; FBS: fetal bovine serum; GM: growth medium; DM: differentiation medium; si-NC: negative control siRNAs; TBST: Tris-buffered saline with Tween; DAPI: 4',6-diamidino-2phenylindole.

\section{Declarations}

\section{Acknowledgments}

The authors gratefully acknowledge all the teachers and students in Laboratory of Animal Genetic Engineering.

\section{Author contributions}

D.M. conceived and designed the experiments. S.C. designed and performed most of the experiments, and manuscript writing. Q.Z., B.H., X.L., and R.Y. helped in sample collecting and paraffin-section making. 
F.L., K.C., T.D. and Y.C. advised on experimental design and participated in the analysis of data. All authors reviewed and approved this manuscript.

\section{Funding}

This research was supported by the National Natural Science Foundation of China (31772565) $\llbracket$ Key Research and Development Program of Guangxi (AB19245030) $\otimes$ the Science and Technology Projects of Zhanjiang (2019A01004), and Guangzhou science and technology planning project (201707020007).

\section{Availability of data and materials}

All data generated or analyzed during this study are included in this published article [and its supplementary information files].

\section{Ethics approval and consent to participate}

The animal experimental procedures used in this experiment were approved by the Animal Care and Use Committee of Guangdong Province, China. Approval ID or permit numbers are SCXK (Guangdong) 20110029 and SYXK (Guangdong) 2011-0112.

\section{Consent for publication}

Not applicable.

\section{Conflict of Interest}

The authors declare no conflict of interests.

\section{References}

1. Picard B, Lefaucheur L, Berri C, Duclos MJ. Muscle fibre ontogenesis in farm animal species. Reproduction Nutrition Development. 2002;42(5):415-31.

2. Tang ZL, Li Y, Wan P, Li XP, Zhao SH, Liu B, et al. LongSAGE analysis of skeletal muscle at three prenatal stages in Tongcheng and Landrace pigs. Genome Biology. 2007;8(6):R115.

3. Picard B, Berri C, Lefaucheur L, Molette C, Sayd T, Terlouw C. Skeletal muscle proteomics in livestock production. Briefings In Functional Genomics. 2010;9(3):259-78.

4. Suzuki A, Cassens RG. A histochemical study of myofiber types in muscle of the growing pig. J Anim Sci. 1980;51(6):1449-61.

5. Bentzinger CF, Wang YX, Rudnicki MA. Building muscle: molecular regulation of myogenesis. Cold Spring Harb Perspect Biol. 2012;4(2):a008342.

6. Sabourin LA, Rudnicki MA. The molecular regulation of myogenesis. Clin Genet. 2000;57(1):16-25. 
7. Pownall ME, Gustafsson MK, Emerson CP, Jr. Myogenic regulatory factors and the specification of muscle progenitors in vertebrate embryos. Annu Rev Cell Dev Biol. 2002;18:747-83.

8. Pownall ME, Gustafsson MK, Emerson CP, Jr. Myogenic regulatory factors and the specification of muscle progenitors in vertebrate embryos. Annu Rev Cell Dev Biol. 2002;18:747-83.

9. Schuster-Gossler K, Cordes R, Gossler A. Premature myogenic differentiation and depletion of progenitor cells cause severe muscle hypotrophy in Delta1 mutants. Proc Natl Acad Sci U S A. 2007;104(2):537-42.

10. Vasyutina E, Lenhard DC, Wende H, Erdmann B, Epstein JA, Birchmeier C. RBP-J (Rbpsuh) is essential to maintain muscle progenitor cells and to generate satellite cells. Proc Natl Acad Sci U S A. 2007;104(11):4443-8.

11. Bi PP, Yue F, Sato Y, Wirbisky S, Liu WY, Shan TZ, et al. Stage-specific effects of Notch activation during skeletal myogenesis. 2016;5:e17355.

12. Shan TZ, Xu ZY, Wu WC, Liu JQ, Wang YZ. Roles of Notch1 Signaling in Regulating Satellite Cell Fates Choices and Postnatal Skeletal Myogenesis. Journal Of Cellular Physiology. 2017;232(11):2964-2967.

13. Castel D, Mourikis P, Bartels SJ, Brinkman AB, Tajbakhsh S, Stunnenberg HG . Dynamic binding of RBPJ is determined by Notch signaling status. Genes Dev. 2013;27(9):1059-71.

14. Borggrefe T, Liefke R. Fine-tuning of the intracellular canonical Notch signaling pathway. Cell Cycle. 2012;11(2):264-76.

15. Hutcheson DA, Zhao J, Merrell A, Haldar M, Kardon G. Embryonic and fetal limb myogenic cells are derived from developmentally distinct progenitors and have different requirements for beta-catenin. Genes Dev. 2009;23(8):997-1013.

16. Otto A, Schmidt C, Luke G, Allen S, Valasek P, Muntoni F. Canonical Wnt signalling induces satellitecell proliferation during adult skeletal muscle regeneration. J Cell Sci. 2008;121(Pt 17):2939-50.

17. Le Grand F, Jones AE, Seale V, Scime A, Rudnicki MA (2009). Wnt7a Activates the Planar Cell Polarity Pathway to Drive the Symmetric Expansion of Satellite Stem Cells. Cell Stem Cell. 2009;4(6):535-47.

18. Cong XX, Gao XK, Rao XS, Wen J, Liu XC, Shi YP, et al. Rab5a activates IRS1 to coordinate IGF-AKTmTOR signaling and myoblast differentiation during muscle regeneration. Cell Death Differ. 2020;27(8):2344-2362.

19. He DT, Zou TD, Gai XR, Ma JD, Li MZ, Huang ZQ, et al. MicroRNA expression profiles differ between primary myofiber of lean and obese pig breeds. PLoS One. 2017;12(7):e0181897.

20. Zhang X, Nie Y, Cai S, Ding S, Fu B, Wei H, et al. Earlier demethylation of myogenic genes contributes to embryonic precocious terminal differentiation of myoblasts in miniature pigs. FASEB J. 2019;33(8):9638-9655.

21. Zhao X, Mo DL, Li AN, Gong W, Xiao SQ, Zhang Y, et al. Comparative Analyses by Sequencing of Transcriptomes during Skeletal Muscle Development between Pig Breeds Differing in Muscle Growth Rate and Fatness. PLoS One. 2011;6(5):e19774. 
22. Zuniga A, Haramis AP, McMahon AP, Zeller R. Signal relay by BMP antagonism controls the SHH/FGF4 feedback loop in vertebrate limb buds. Nature. 1999;401(6753):598-602.

23. Buckingham M, Rigby PW. Gene regulatory networks and transcriptional mechanisms that control myogenesis. Dev Cell. 2014;28(3):225-38.

24. Sainson RC, Aoto J, Nakatsu MN, Holderfield M, Conn E, Koller E. Cell-autonomous notch signaling regulates endothelial cell branching and proliferation during vascular tubulogenesis. FASEB J. 2005;19(8):1027-9.

25. Hellstrom M, Phng LK, Hofmann JJ, Wallgard E, Coultas L, Lindblom P, et al. DIl4 signalling through Notch1 regulates formation of tip cells during angiogenesis. Nature. 2007;445(7129):776-80.

26. Mu X, Tang Y, Lu A, Takayama K, Usas A, Wang B. The role of Notch signaling in muscle progenitor cell depletion and the rapid onset of histopathology in muscular dystrophy. Human Molecular Genetics. 2015;24(10):2923-37.

27. Davis RL, Weintraub H, Lassar AB. Expression of a single transfected cDNA converts fibroblasts to myoblasts. Cell. 1987;51(6):987-1000.

28. Bar-Nur O, Gerli MFM, Di Stefano B, Almada AE, Galvin A, Coffey A, et al. Direct Reprogramming of Mouse Fibroblasts into Functional Skeletal Muscle Progenitors. Stem Cell Reports. 2018;10(5):15051521.

29. Hirsinger E, Malapert P, Dubrulle J, Delfini MC, Duprez D, Henrique D, et al. Notch signalling acts in postmitotic avian myogenic cells to control MyoD activation. Development. 2001;128(1):107-16.

30. Delfini MC, Hirsinger E, Pourquie O, Duprez D. Delta 1-activated notch inhibits muscle differentiation without affecting Myf5 and Pax3 expression in chick limb myogenesis. Development. 2000;127(23):5213-24.

31. Lindsell CE, Shawber CJ, Boulter J, Weinmaster G. Jagged: a mammalian ligand that activates Notch1. Cell. 1995;80(6):909-17.

32. Kopan R, Nye JS, Weintraub H. The intracellular domain of mouse Notch: a constitutively activated repressor of myogenesis directed at the basic helix-loop-helix region of MyoD. Development. 1994;120(9):2385-96.

33. Shawber C, Nofziger D, Hsieh JJ, Lindsell C, Bogler O, Hayward D, et al. Notch signaling inhibits muscle cell differentiation through a CBF1-independent pathway. Development. 1996;122(12):376573.

34. Mourikis P, Gopalakrishnan S, Sambasivan R, Tajbakhsh S. Cell-autonomous Notch activity maintains the temporal specification potential of skeletal muscle stem cells. Development. 2012;139(24):4536-48.

35. Wittenberger T, Steinbach OC, Authaler A, Kopan R, Rupp RA. MyoD stimulates delta-1 transcription and triggers notch signaling in the Xenopus gastrula. EMBO J. 1999;18(7):1915-22.

36. Jen WC, Wettstein D, Turner D, Chitnis A, Kintner C. The Notch ligand, X-Delta-2, mediates segmentation of the paraxial mesoderm in Xenopus embryos. Development. 1997;124(6):1169-78. 
37. Takke C, Campos-Ortega JA. her1, a zebrafish pair-rule like gene, acts downstream of notch signalling to control somite development. Development. 1999;126(13):3005-14.

38. Oates AC, Ho RK. Hairy/E(spl)-related (Her) genes are central components of the segmentation oscillator and display redundancy with the Delta/Notch signaling pathway in the formation of anterior segmental boundaries in the zebrafish. Development. 2002;129(12):2929-46.

39. Holley SA, Julich D, Rauch GJ, Geisler R, Nusslein-Volhard C. her1 and the notch pathway function within the oscillator mechanism that regulates zebrafish somitogenesis. Development. 2002;129(5):1175-83.

40. Oustanina S, Hause G, Braun T. Pax7 directs postnatal renewal and propagation of myogenic satellite cells but not their specification. Embo Journal. 2004;23(16):3430-9.

41. Kuang S, Charge SB, Seale P, Huh M, Rudnicki MA. Distinct roles for Pax7 and Pax3 in adult regenerative myogenesis. Journal Of Cell Biology. 2006;172(1):103-13.

42. Cornelison DD, Wold BJ. Single-cell analysis of regulatory gene expression in quiescent and activated mouse skeletal muscle satellite cells. Developmental Biology. 1997;191(2):270-83.

43. Halevy O, Piestun Y, Allouh MZ, Rosser BW, Rinkevich Y, Reshef R, et al. Pattern of Pax7 expression during myogenesis in the posthatch chicken establishes a model for satellite cell differentiation and renewal. Dev Dyn. 2004;231(3):489-502..

44. Zammit PS, Golding JP, Nagata Y, Hudon V, Partridge TA, Beauchamp JR. Muscle satellite cells adopt divergent fates: a mechanism for self-renewal? J Cell Biol. 2004;166(3):347-57.

45. Olguin HC, Olwin BB. Pax-7 up-regulation inhibits myogenesis and cell cycle progression in satellite cells: a potential mechanism for self-renewal. Developmental Biology. 2004;275(2):375-88.

46. Collins CA, Gnocchi VF, White RB, Boldrin L, Perez-Ruiz A, Relaix F, et al. Integrated functions of Pax3 and $\mathrm{Pax} 7$ in the regulation of proliferation, cell size and myogenic differentiation. PLoS One. 2009;4(2):e4475.

47. von Maltzahn J, Jones AE, Parks RJ, Rudnicki MA. Pax7 is critical for the normal function of satellite cells in adult skeletal muscle. Proc Natl Acad Sci U S A. 2013;110(41):16474-9.

48. Kassar-Duchossoy L, Giacone E, Gayraud-Morel B, Jory A, Gomes D, Tajbakhsh S. Pax3/Pax7 mark a novel population of primitive myogenic cells during development. Genes Dev. 2005;19(12):1426-31.

49. Relaix F, Rocancourt D, Mansouri A, Buckingham M. A Pax3/Pax7-dependent population of skeletal muscle progenitor cells. Nature. 2005;435(7044):948-53.

\section{Figures}




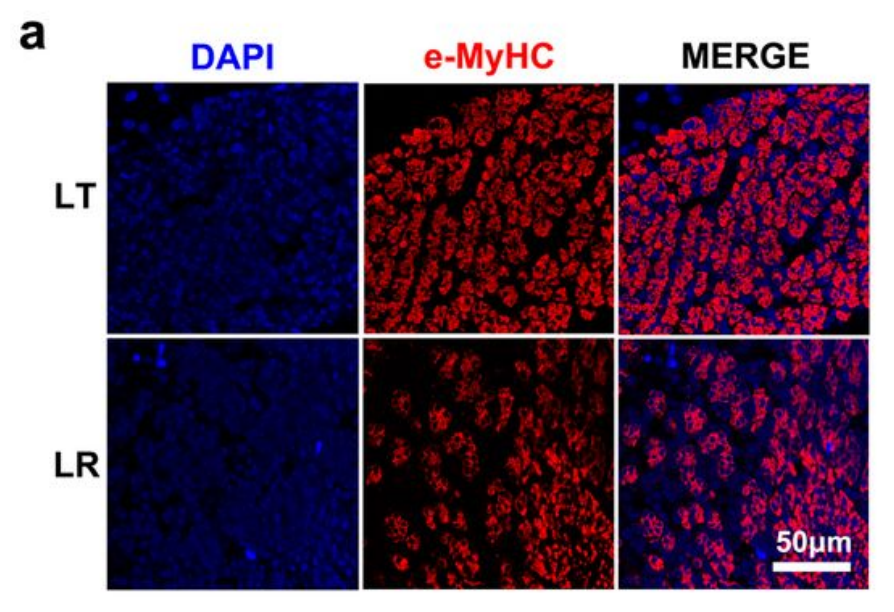

b

C

LT

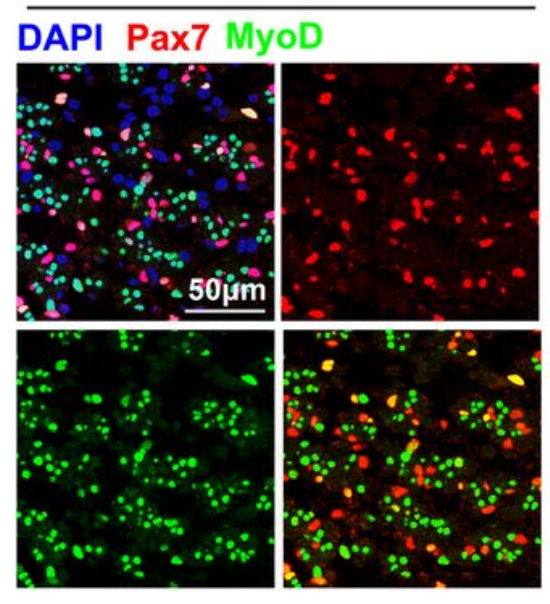

LR

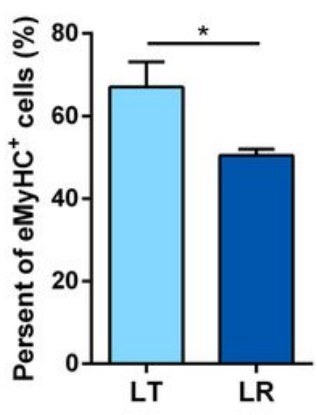

e

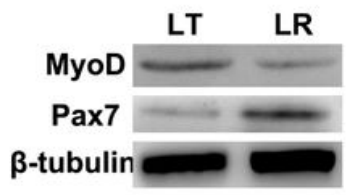

d

DAPI Pax7 MyoD
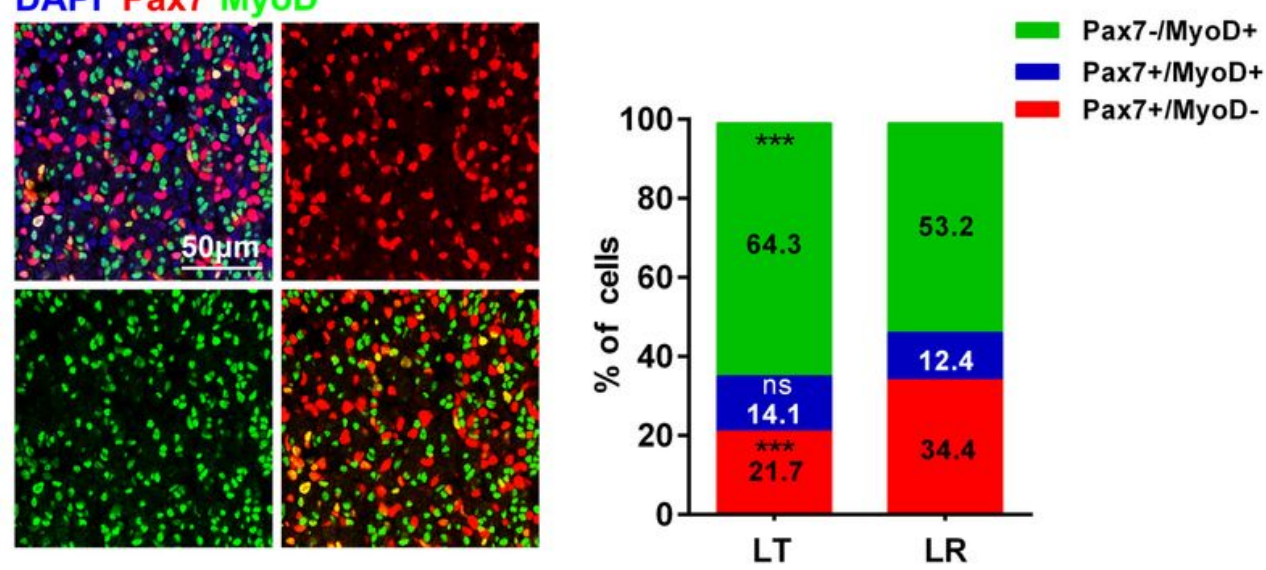

Figure 1

Myogenesis process is more intense in LT than that in LR at 35dpc. a. Immunofluorescence staining of embryonic MyHC (eMyHC) was performed on longissimus dorsi muscle (LDM) cross section of LT and LR at $35 \mathrm{dpc}$. The cell nucleus was stained with DAPI. Scale bar $=50 \mu \mathrm{m}$. b. Percentages of eMyHCpositive cells in (A) were counted in six microscopic fields for each group. c. Immunofluorescence staining for Pax7 (a marker of muscle progenitor cells) and MyoD (a marker of differentiated myogenic cells) on cross sections described as (a). Scale bar $=50 \mu \mathrm{m}$. d. Percentages of three cell populations in (c) were counted in six microscopic fields for each group. e. The protein levels of Pax7 and MyoD were detected via Western blot in LT and LR LDM. $\beta$-tubulin was used as a loading control. Data are presented as mean \pm SEM, $n=6$ per group. ${ }^{*} P<0.05,{ }^{\star} P P<0.01,{ }^{\star \star *} P<0.001$ (Student's $t$ test). 


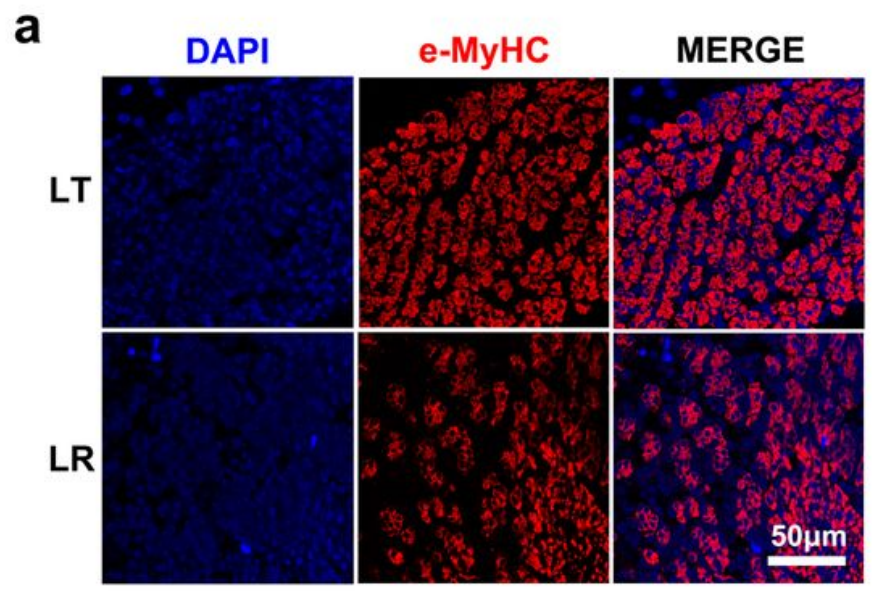

b

C

LT

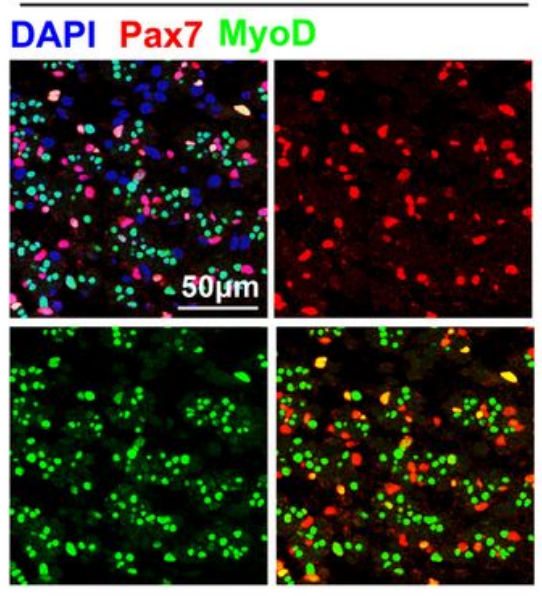

LR

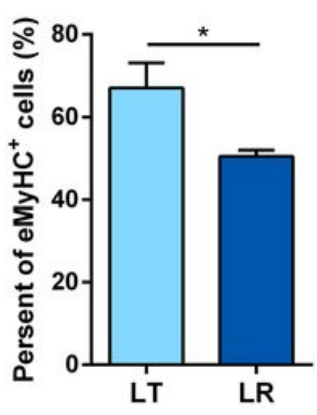

e

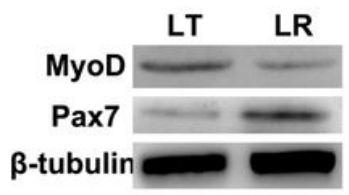

d

DAPI Pax7 MyoD
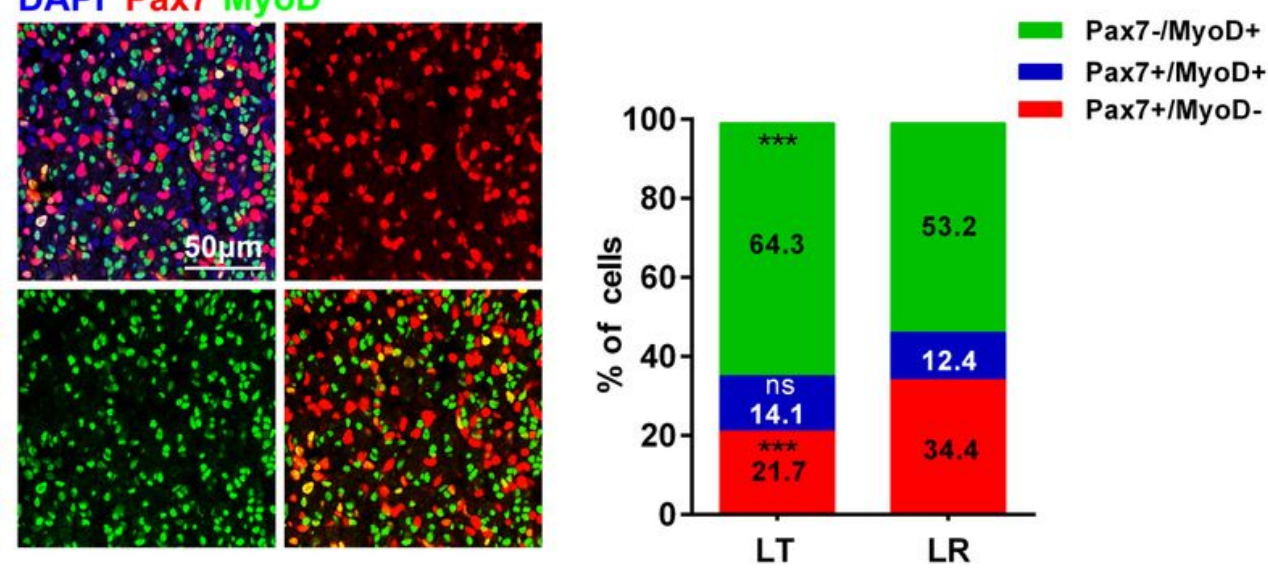

Figure 1

Myogenesis process is more intense in LT than that in LR at 35dpc. a. Immunofluorescence staining of embryonic MyHC (eMyHC) was performed on longissimus dorsi muscle (LDM) cross section of LT and LR at $35 \mathrm{dpc}$. The cell nucleus was stained with DAPI. Scale bar $=50 \mu \mathrm{m}$. b. Percentages of eMyHCpositive cells in (A) were counted in six microscopic fields for each group. c. Immunofluorescence staining for Pax7 (a marker of muscle progenitor cells) and MyoD (a marker of differentiated myogenic cells) on cross sections described as (a). Scale bar $=50 \mu \mathrm{m}$. d. Percentages of three cell populations in (c) were counted in six microscopic fields for each group. e. The protein levels of Pax7 and MyoD were detected via Western blot in LT and LR LDM. $\beta$-tubulin was used as a loading control. Data are presented as mean \pm SEM, $n=6$ per group. ${ }^{*} P<0.05,{ }^{\star} P P<0.01,{ }^{\star \star *} P<0.001$ (Student's $t$ test). 
a

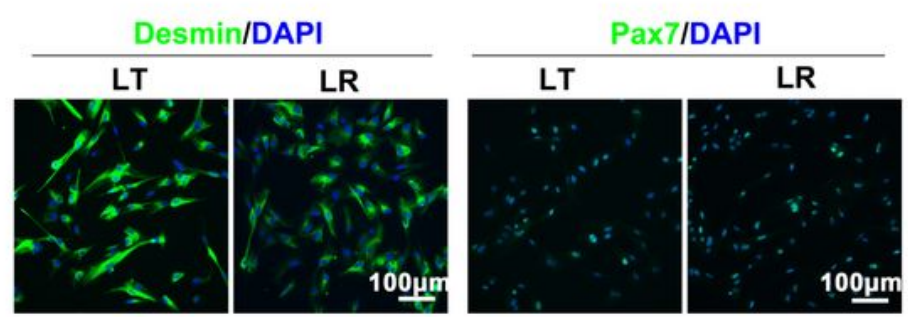

d
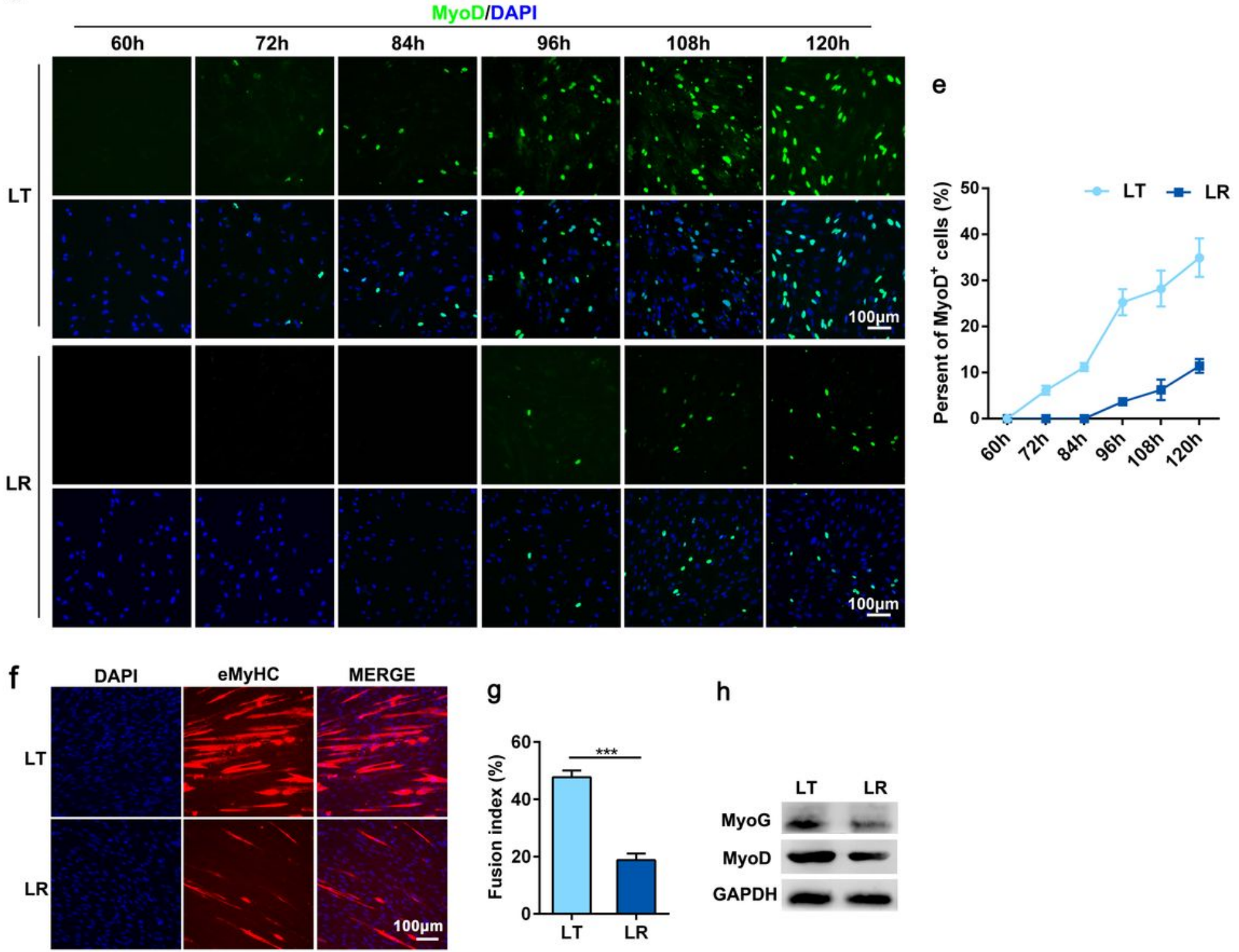

g

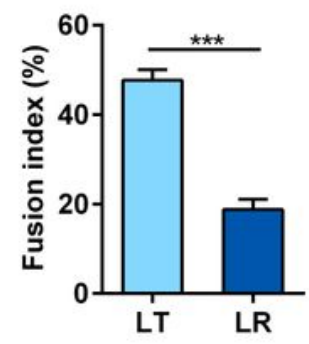

b

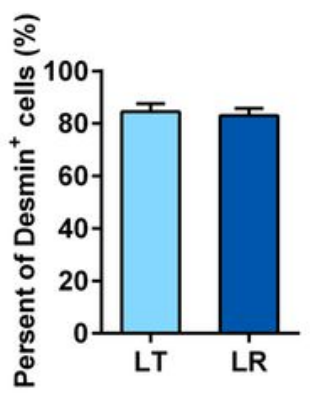

C

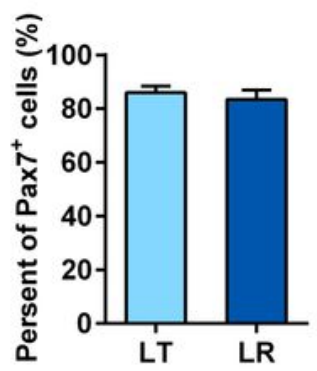

MyoD/DAPI 
$L R$, respectively. d. Immunofluorescent staining for MyoD in muscle progenitors cultured in GM for indicated times. e. Percentages of MyoD-positive cells in (d) were counted in six microscopic fields for each group. f. Immunofluorescent staining for eMyHC in muscle progenitors at $6 \mathrm{~d}$ after differentiation induction. g. The fusion index (the percentage of nuclei in fused myotubes out of the total nuclei) in (f) was calculated. For each group, six random microscopic fields were selected randomly. h. Western blot detected the protein levels of MyoG and MyoD in cells described as (f). GAPDH was used as a loading control. Data are showed as mean $\pm \mathrm{SEM}, \mathrm{n}=6$ per group. ${ }^{\star} \mathrm{P}<.05,{ }^{\star \star} \mathrm{P}<.01,{ }^{\star \star *} \mathrm{P}<0.001$ (Student's $\mathrm{t}$ test). 
a

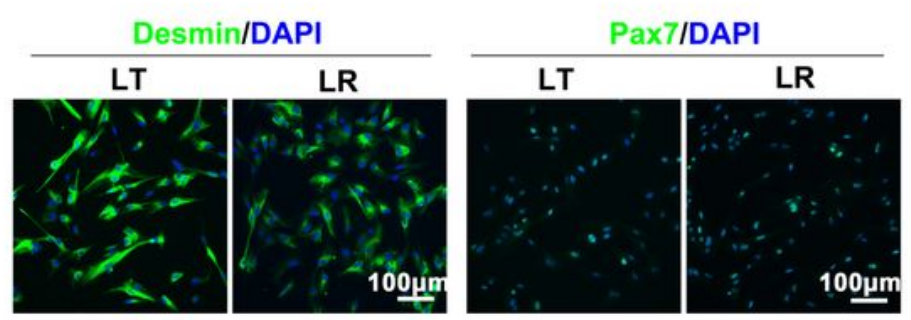

d

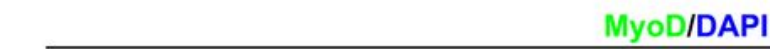

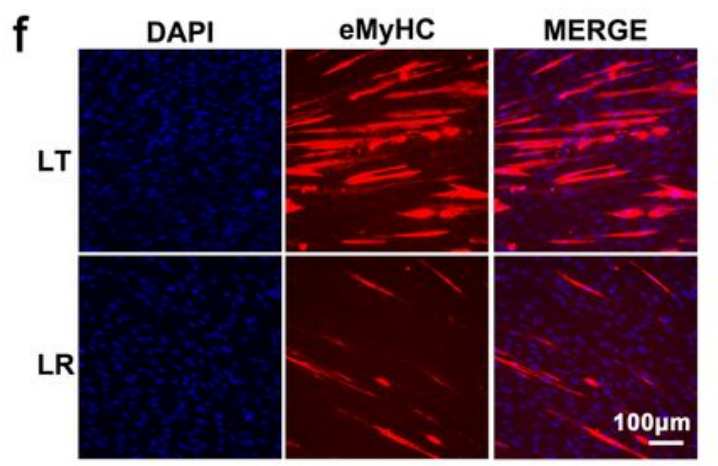

b

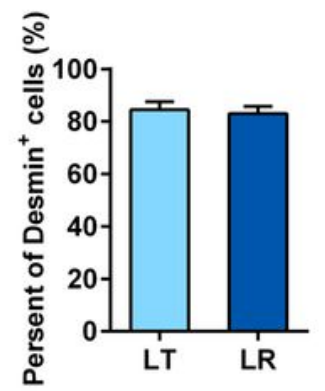

C

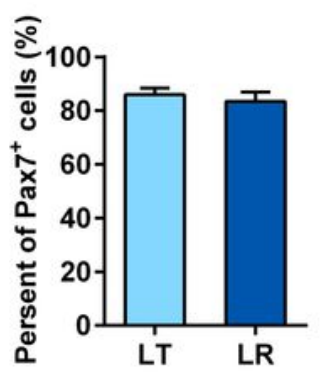

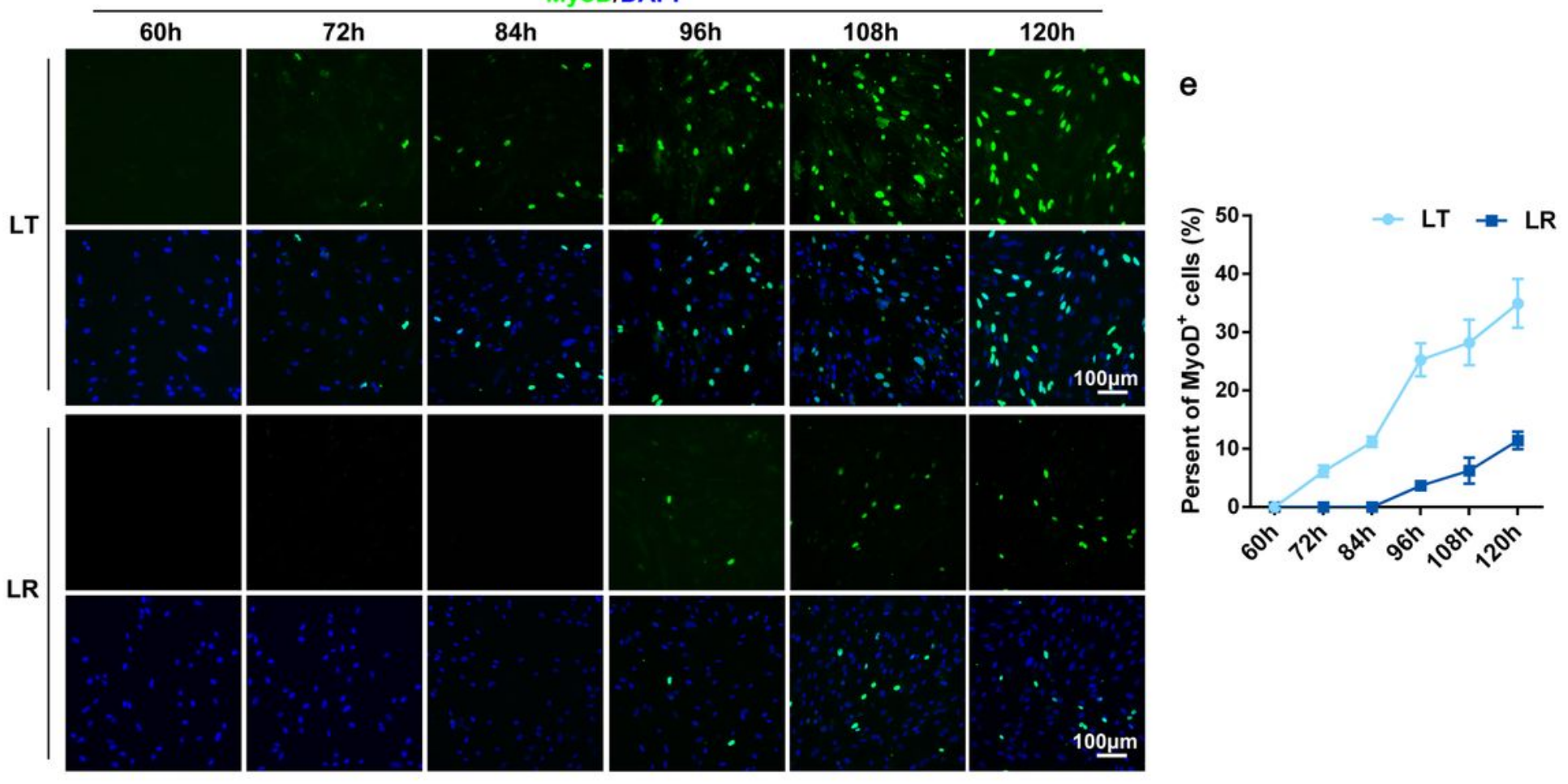

g

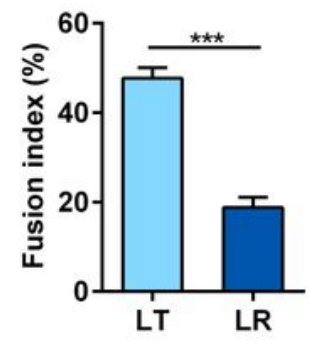

h

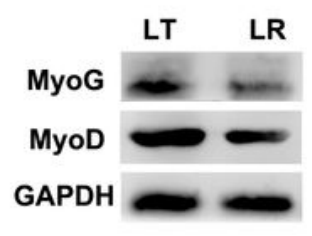

Figure 2

Embryonic muscle progenitors from LT express MyoD earlier and have stronger differentiation capacity in vitro a. Immunofluorescent staining of Desmin (a marker of myogenic cells) and Pax7 was performed to identify the isolated cells from LT and LR LDM. The cell nucleus was stained with DAPI. Scale bar $=100$ $\mu \mathrm{m}$. b. Percentages of Desmin-positive cells in (A) were counted in six microscopic fields for LT and LR, respectively. c. Percentages of Pax7-positive cells in (a) were counted in six microscopic fields for LT and 
$\mathrm{LR}$, respectively. d. Immunofluorescent staining for MyoD in muscle progenitors cultured in $\mathrm{GM}$ for indicated times. e. Percentages of MyoD-positive cells in (d) were counted in six microscopic fields for each group. f. Immunofluorescent staining for eMyHC in muscle progenitors at $6 \mathrm{~d}$ after differentiation induction. g. The fusion index (the percentage of nuclei in fused myotubes out of the total nuclei) in (f) was calculated. For each group, six random microscopic fields were selected randomly. h. Western blot detected the protein levels of MyoG and MyoD in cells described as (f). GAPDH was used as a loading control. Data are showed as mean $\pm \mathrm{SEM}, \mathrm{n}=6$ per group. ${ }^{\star} \mathrm{P}<.05,{ }^{\star \star} \mathrm{P}<.01,{ }^{\star \star *} \mathrm{P}<0.001$ (Student's $\mathrm{t}$ test).

a

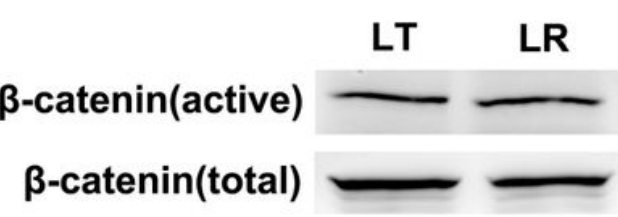

$\beta$-tubulin b

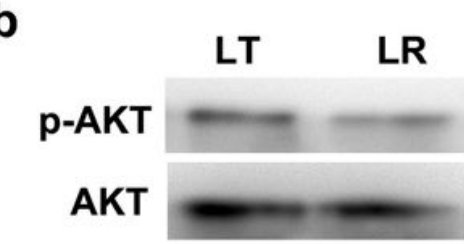

$\beta$-tubulin

d

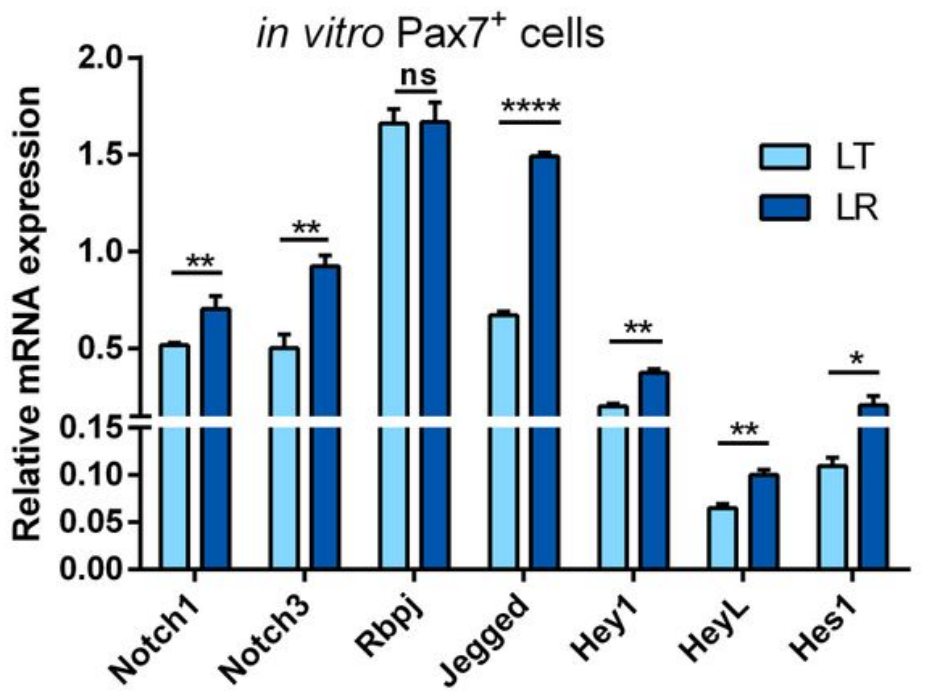

f

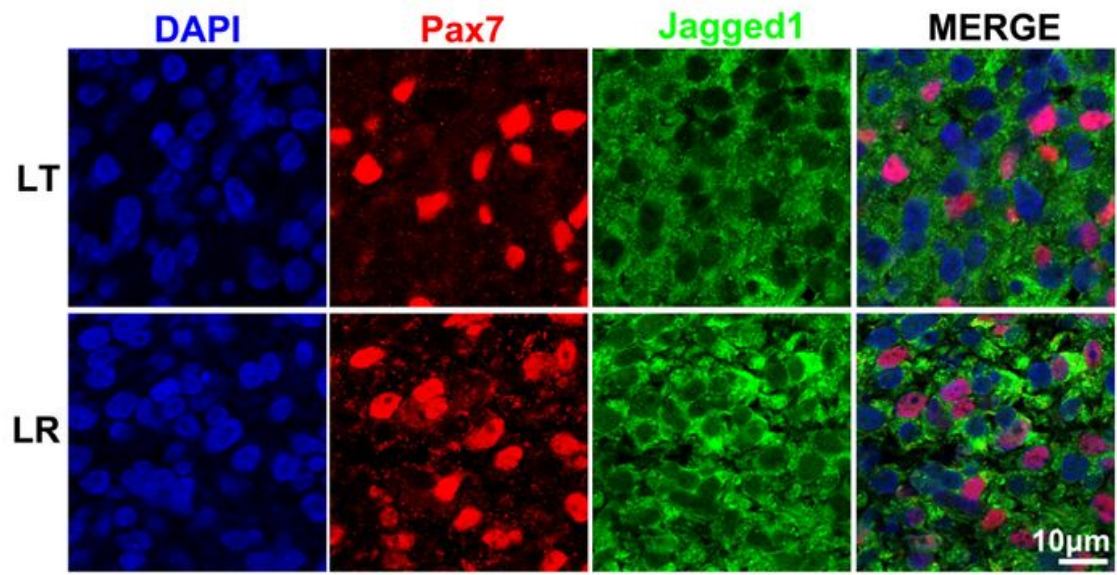

e
C p-S6K1

S6K1

$\beta$-tubulin

LT LR 
GM. GAPDH was used as a loading control. d. qPCR was performed for analyzing the mRNA levels of Notch genes. e. Protein levels of Jagged1, Hes1 and Hey1. f. Immunofluorescence staining for Pax7 and Jagged 1 was performed on LDM cross section of LT and LR at $35 \mathrm{dpc}$. Scale bar $=10 \mu \mathrm{m}$. Data are showed as mean \pm SEM, $\mathrm{n}=6$ per group. ${ }^{*} \mathrm{P}<.05,{ }^{*} \mathrm{P}<.01,{ }^{*} * \mathrm{P}<0.001$ (Student's $t$ test).
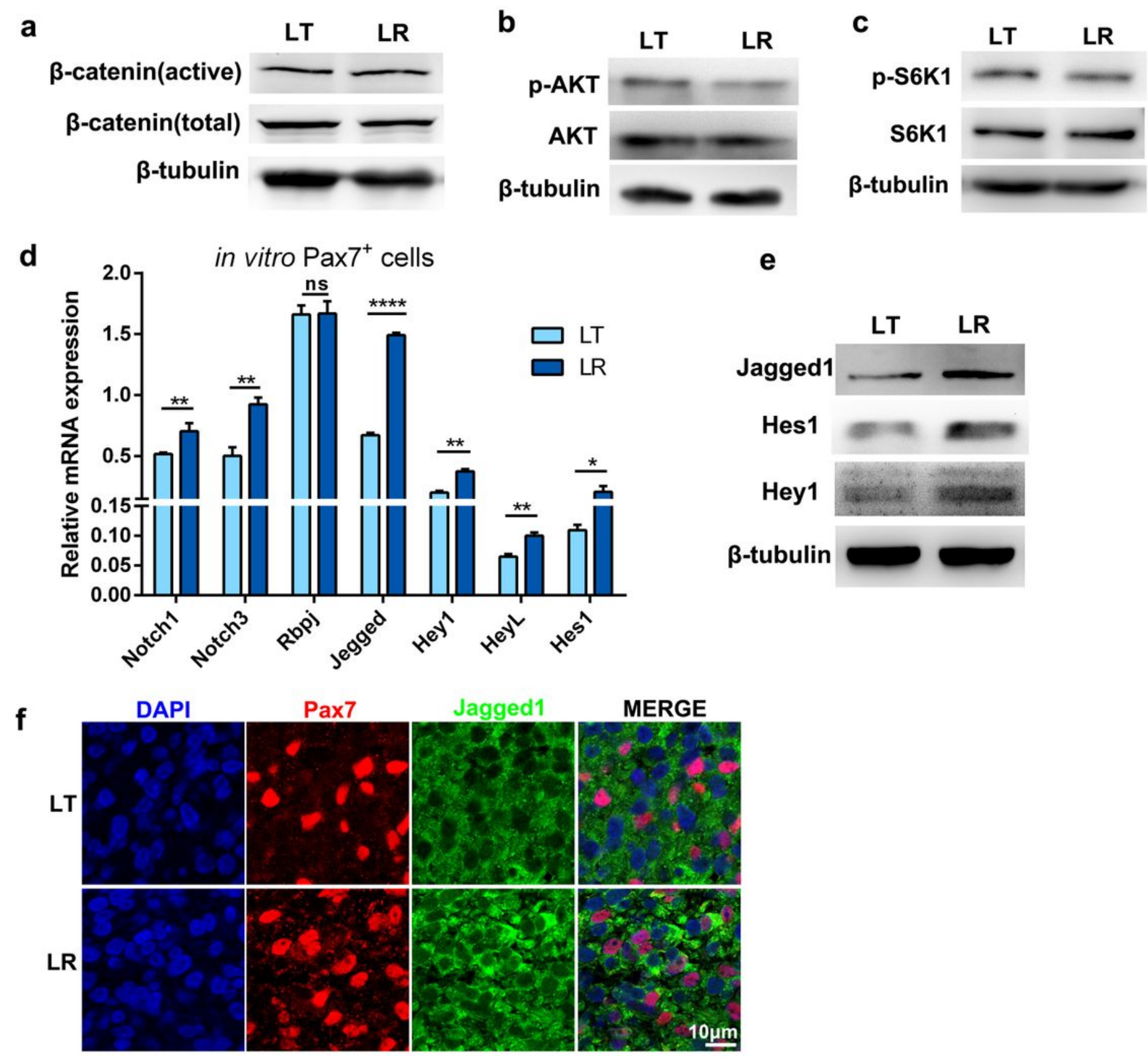

Figure 3

Notch signaling is more active in LR myogenic progenitors a-c. Western blot detected the protein levels of active $\beta$-catenin, total $\beta$-catenin, p-AKT, AKT, p-S6K1 and S6K1 in LT and LR muscle progenitors cultured in GM. GAPDH was used as a loading control. d. qPCR was performed for analyzing the mRNA levels of Notch genes. e. Protein levels of Jagged1, Hes1 and Hey1. f. Immunofluorescence staining for Pax7 and Jagged 1 was performed on LDM cross section of LT and LR at 35dpc. Scale bar $=10 \mu \mathrm{m}$. Data are showed as mean \pm SEM, $n=6$ per group. ${ }^{*} P<.05$, ${ }^{*} P<.01,{ }^{* *} \mathrm{P}<0.001$ (Student's $t$ test). 


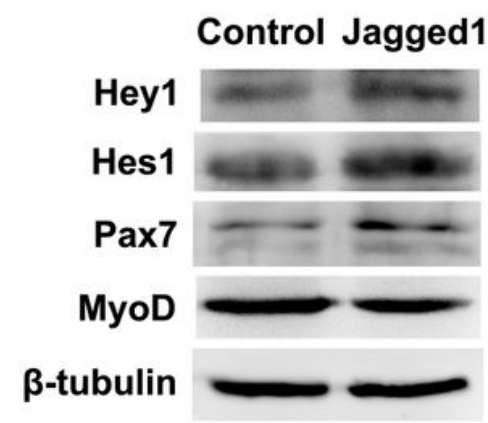

C

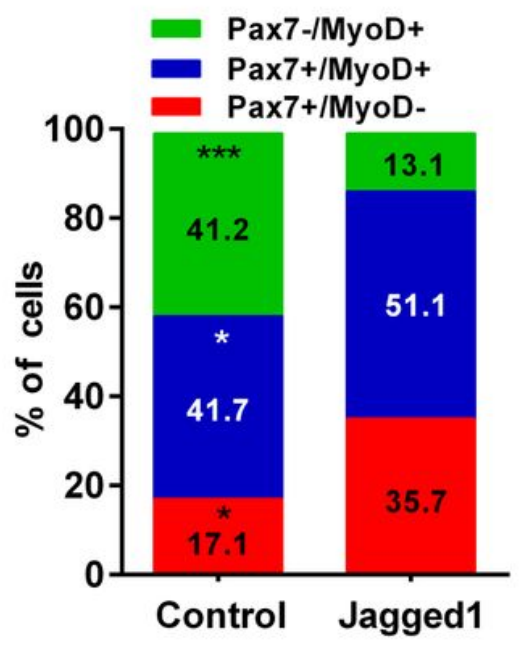

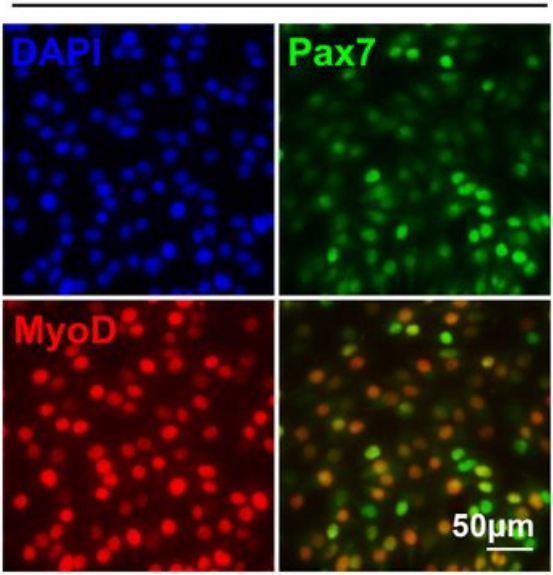

d

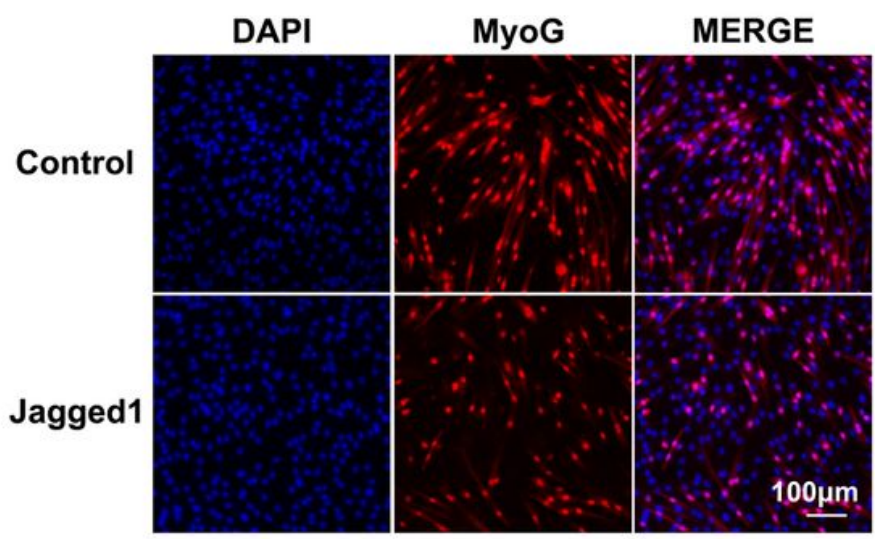

g f

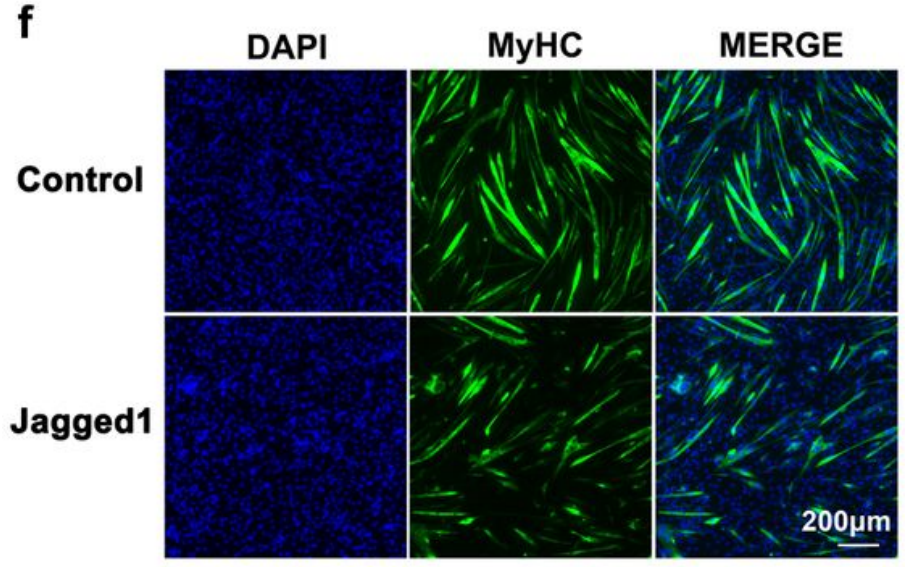

g

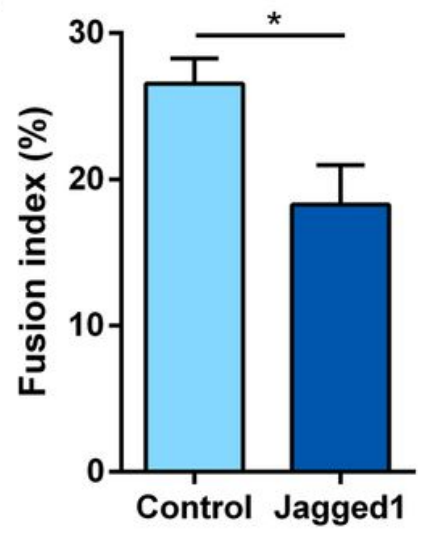

e

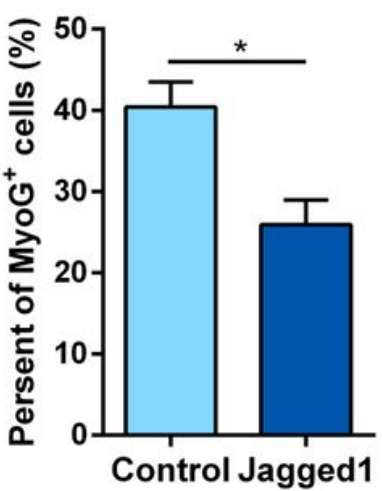

Figure 4

Boosted Notch signaling prevents C2C12 myoblast differentiation a. Western blot detected the protein levels of Hey1, Hes1, Pax7 and MyoD in control (ddH2O-treated) and Jagged1-treated C2C12 cells cultured in GM for 2 d. b. Immunofluorescent staining for Pax7 and MyoD in control and Jagged1-treated cells. Scale bar $=50 \mu \mathrm{m}$. c. Percentages of three cell populations in (b) were counted in six microscopic fields for each group. d. Immunofluorescent staining for MyoG was performed in treated cells to examine myoblast differentiation at $1 \mathrm{~d}$ after differentiation induction. Scale bar $=100 \mu \mathrm{m}$. e. Percentages of MyoG- 
positive cells in (d) were counted in six microscopic fields for each group. f. Immunofluorescent staining for $\mathrm{MyHC}$ was performed in treated cells at $3 \mathrm{~d}$ after differentiation induction. Scale bar $=200 \mu \mathrm{m}$. $\mathrm{g}$. The fusion index of differentiated myoblasts in ( $f$ ) was calculated. $h$. Western blot detected the protein levels of $\mathrm{MyHC}$ and MyoG in cells described as (f). Data are showed as mean $\pm S E M, n=6$ per group. $* P<.05$, $* * \mathrm{P}<.01, * * * \mathrm{P}<0.001$ (Student's $\mathrm{t}$ test).

a

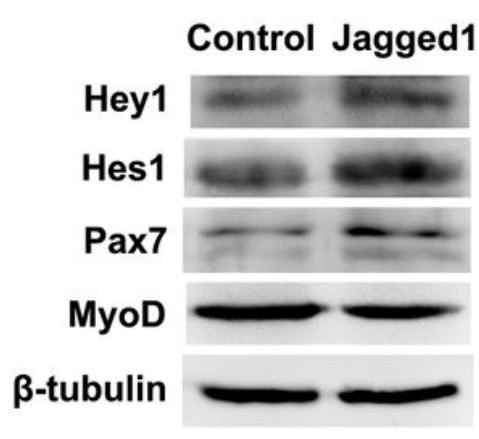

C

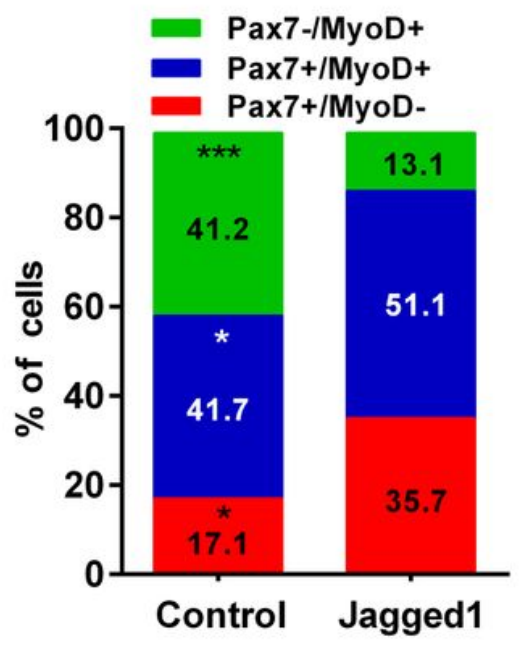

$\mathbf{f}$

Control
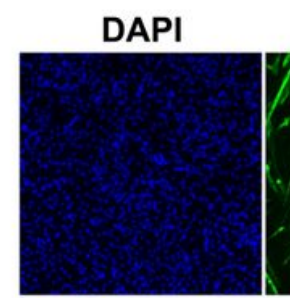

MyHC

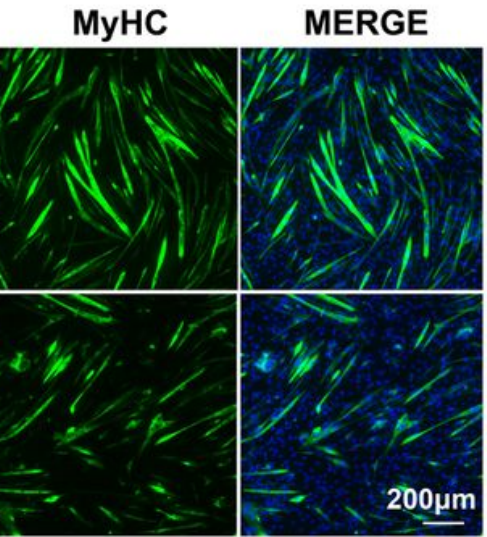

b

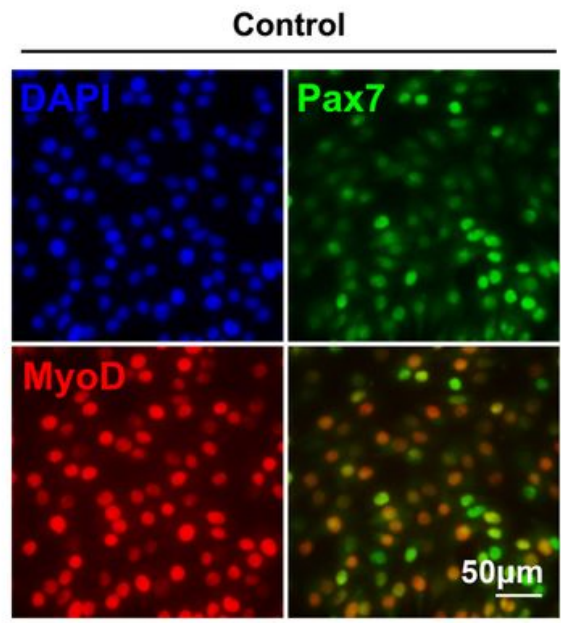

d

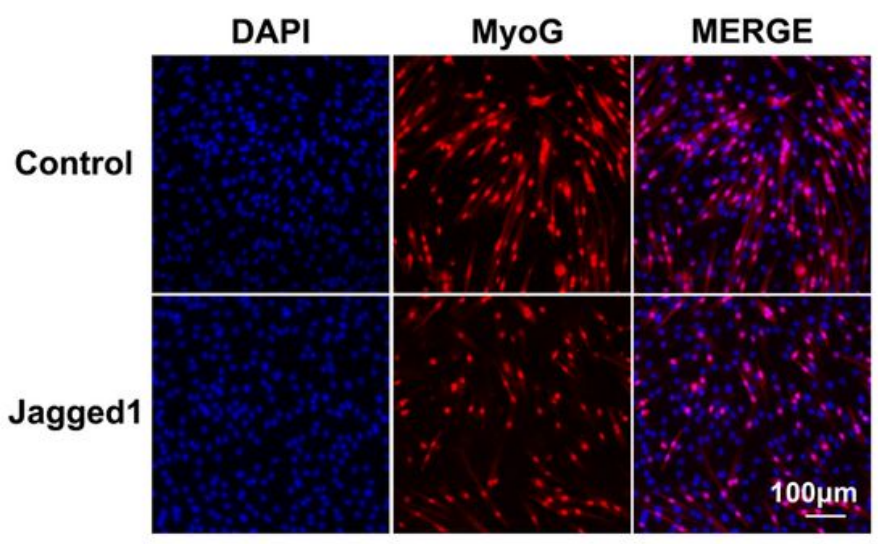

g

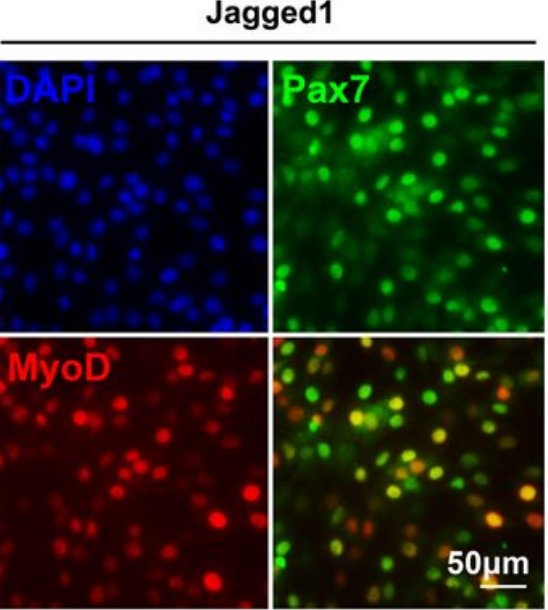

e

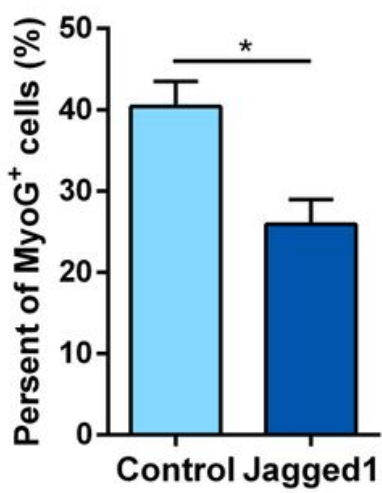

h

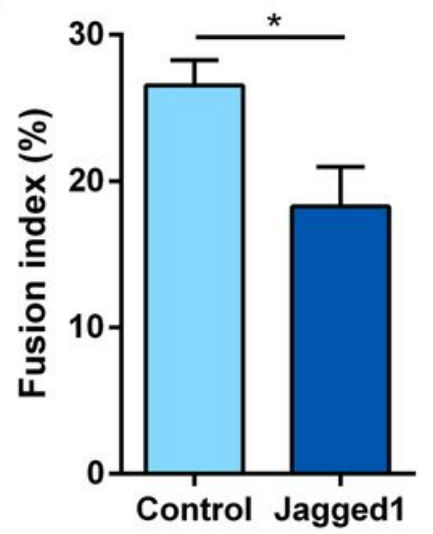

Control Jagged1 MHC MyoG tubulin

Figure 4 
Boosted Notch signaling prevents $\mathrm{C} 2 \mathrm{C} 12$ myoblast differentiation a. Western blot detected the protein levels of Hey1, Hes1, Pax7 and MyoD in control (ddH2O-treated) and Jagged1-treated C2C12 cells cultured in GM for $2 \mathrm{~d}$. b. Immunofluorescent staining for Pax7 and MyoD in control and Jagged1-treated cells. Scale bar $=50 \mu \mathrm{m}$. c. Percentages of three cell populations in (b) were counted in six microscopic fields for each group. d. Immunofluorescent staining for MyoG was performed in treated cells to examine myoblast differentiation at $1 \mathrm{~d}$ after differentiation induction. Scale bar=100 $\mu \mathrm{m}$. e. Percentages of MyoGpositive cells in (d) were counted in six microscopic fields for each group. f. Immunofluorescent staining for $\mathrm{MyHC}$ was performed in treated cells at $3 \mathrm{~d}$ after differentiation induction. Scale bar $=200 \mu \mathrm{m}$. $\mathrm{g}$. The fusion index of differentiated myoblasts in (f) was calculated. $h$. Western blot detected the protein levels of $\mathrm{MyHC}$ and MyoG in cells described as (f). Data are showed as mean $\pm S E M, n=6$ per group. ${ }^{*} P<.05$, $\star \star P<.01,{ }^{\star \star \star} \mathrm{P}<0.001$ (Student's t test). 

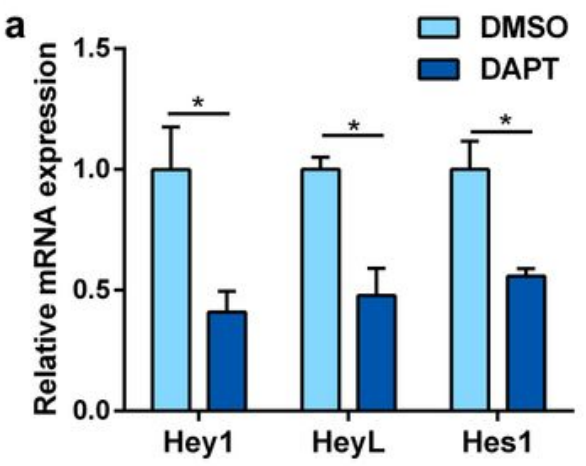

b

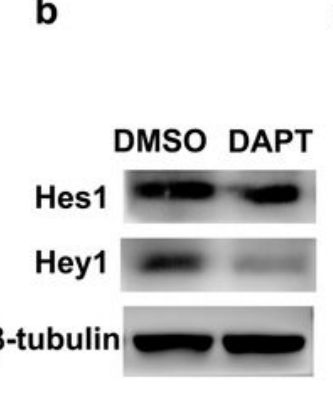

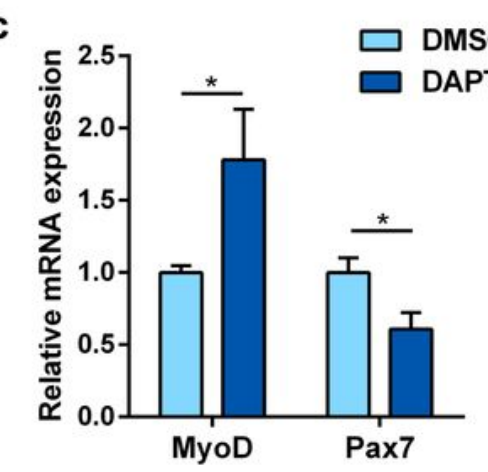

d

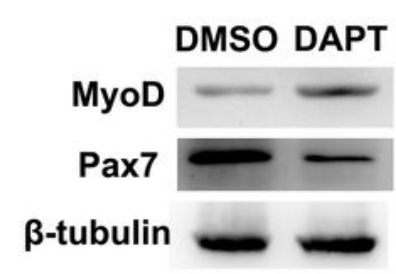

e

MyoD/DAPI
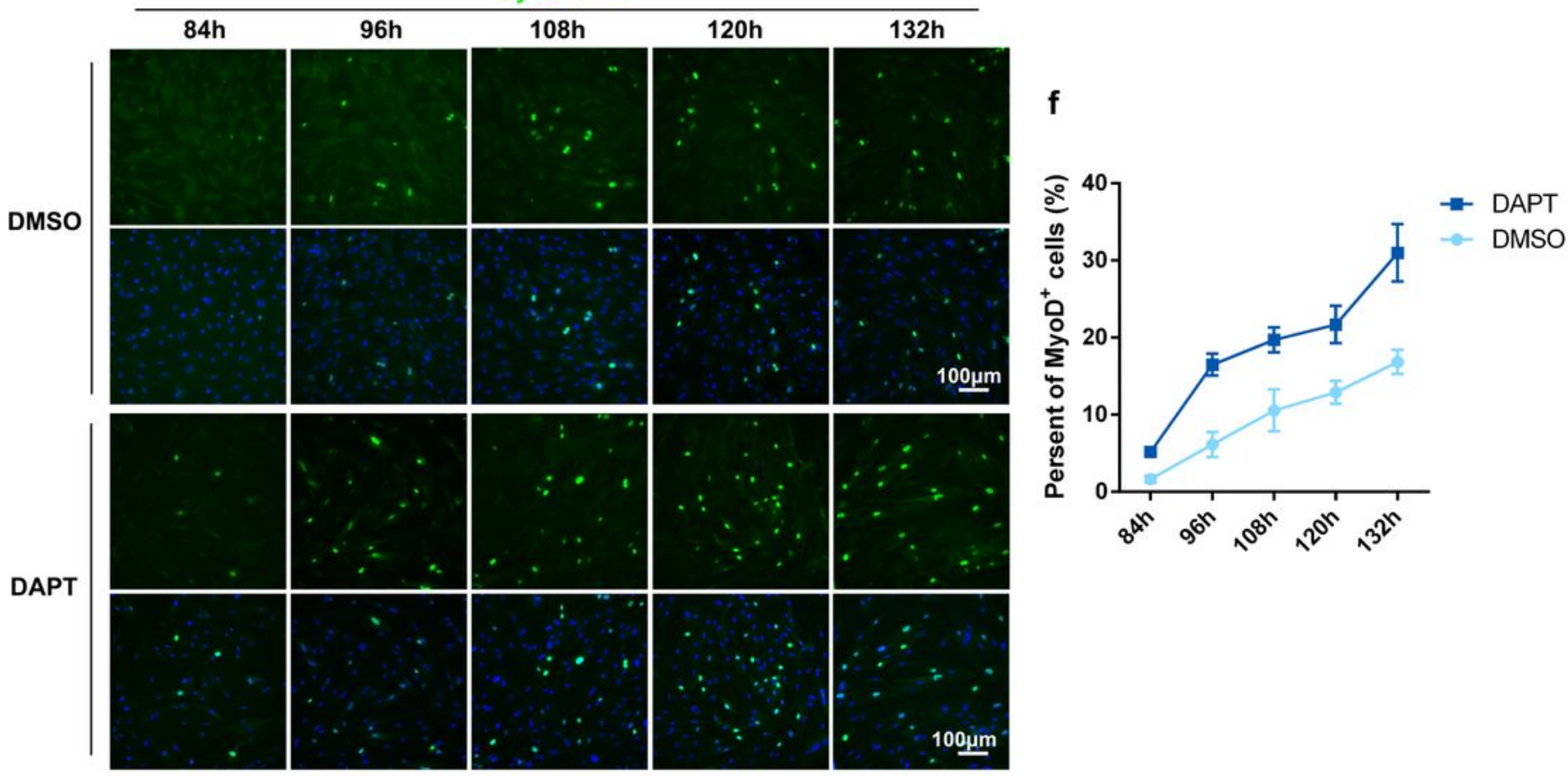

g

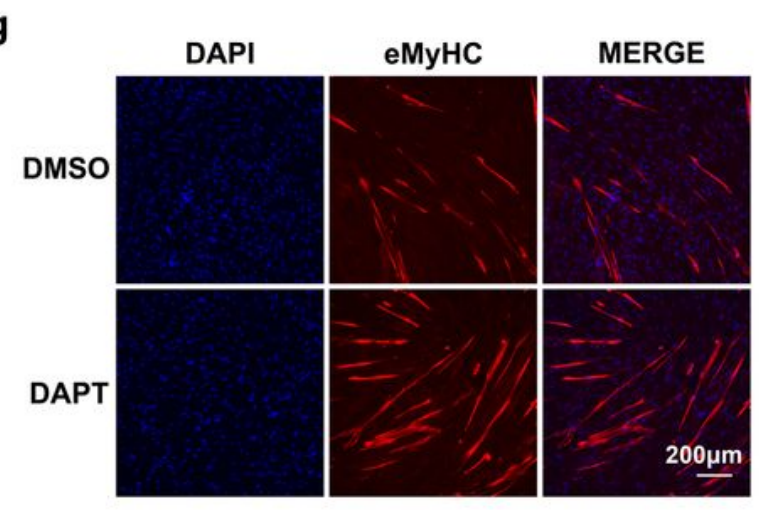

h

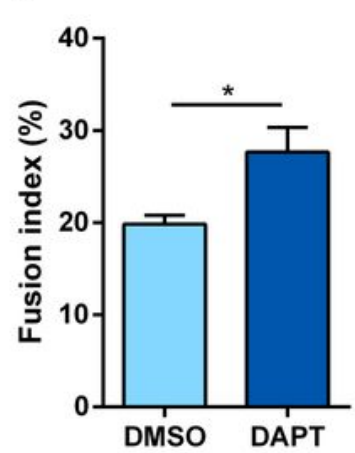

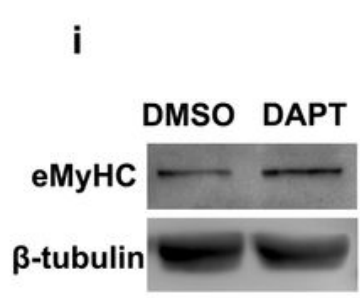

$\beta$-tubulin

\section{Figure 5}

Inhibition of Notch signaling promotes the differentiation of embryonic myogenic progenitors in vitro a. The mRNA levels of Notch genes in control (DMSO-treated) and DAPT-treated LR muscle progenitors cultured in GM for $3 \mathrm{~d}$. b. The protein levels of Notch genes in cells described as (A). c. The mRNA levels of Pax7 and MyoD in control and DAPT-treated cells cultured in GM for $3 \mathrm{~d}$. $\mathrm{d}$. The protein levels of Pax7 and MyoD in cells described as (C). e. Immunofluorescent staining for MyoD in control and DAPT-treated 
muscle progenitors cultured in GM for indicated times. Scale bar $=100 \mu \mathrm{m}$. f. Percentages of MyoDpositive cells in (e) were counted in six microscopic fields for each group. g. Immunofluorescent staining for eMyHC was performed in treated muscle progenitor cells at $6 \mathrm{~d}$ after differentiation induction. Scale bar $=200 \mu \mathrm{m}$. h. The fusion index of differentiated progenitor cells in (g) was calculated. I. Western blot detected the protein levels of eMyHC in cells described as $(\mathrm{g})$. Data are showed as mean $\pm \mathrm{SEM}, \mathrm{n}=6$ per group. ${ }^{*} \mathrm{P}<.05,{ }^{*} \mathrm{P}<.01,{ }^{* \star *} \mathrm{P}<0.001$ (Student's $\mathrm{t}$ test).

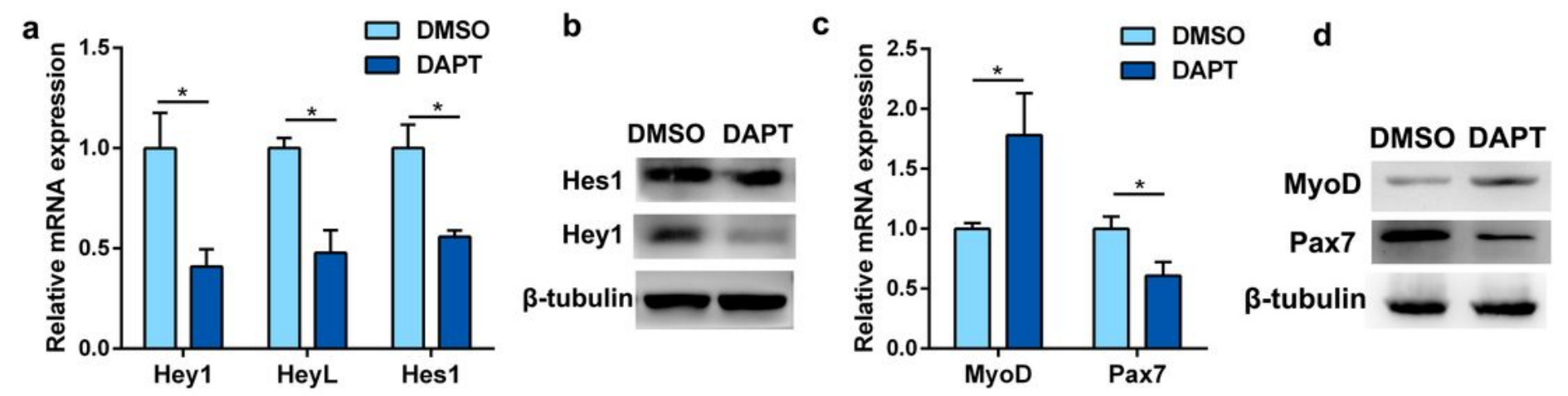

e

MyoD/DAPI

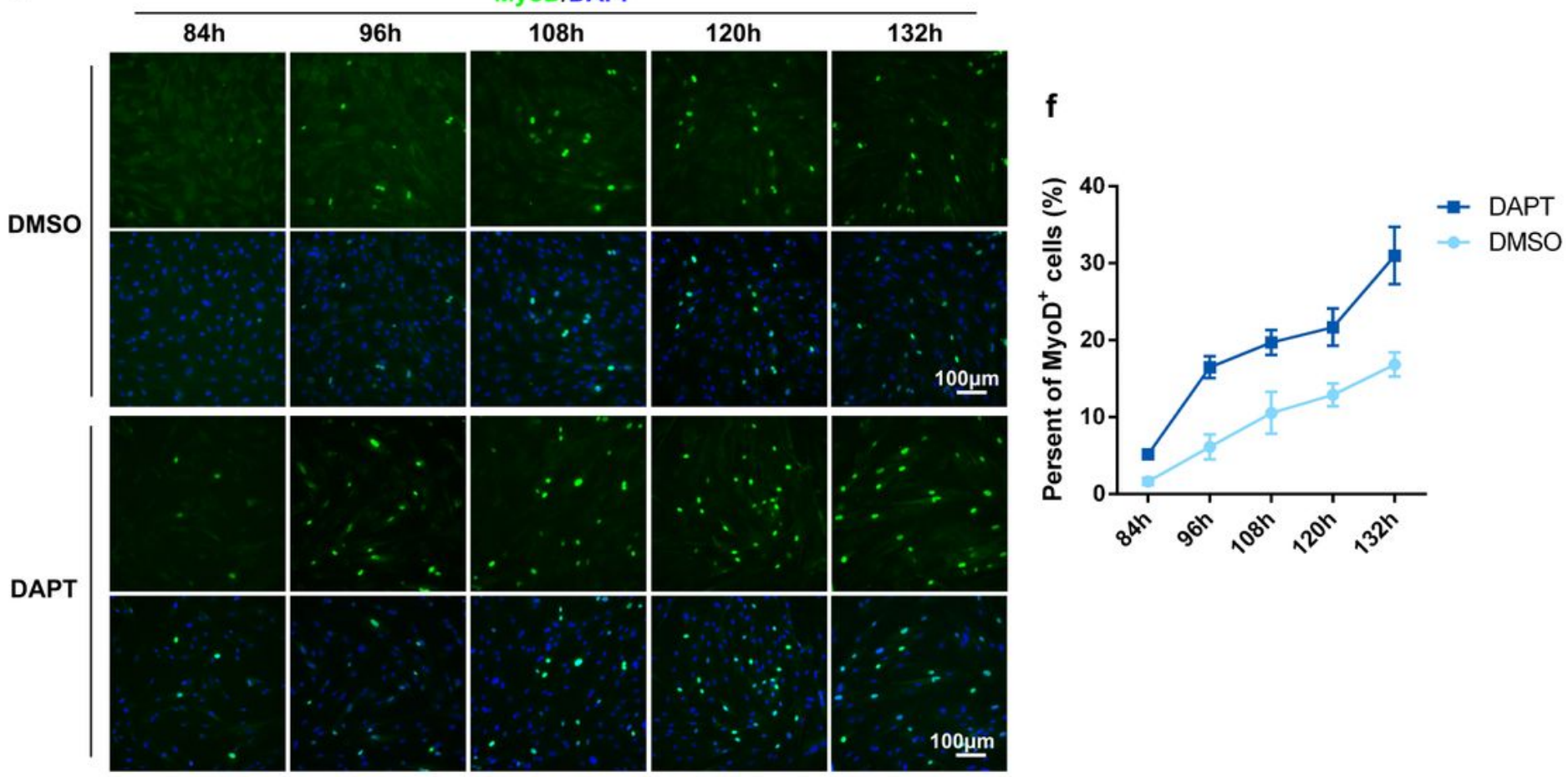

g

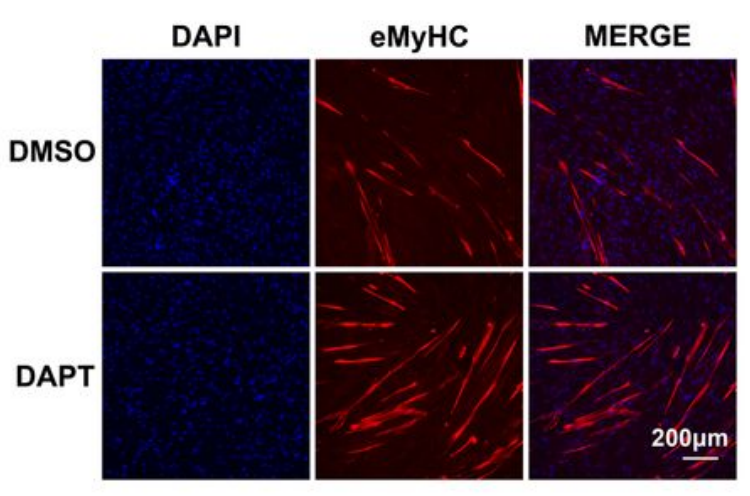

h

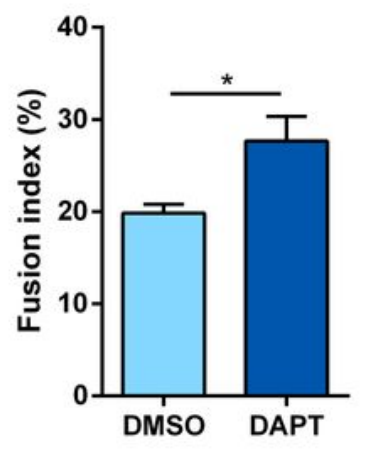

i

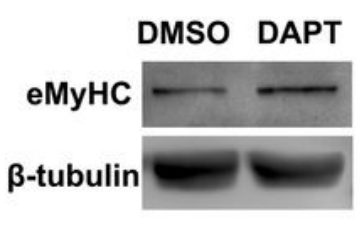

Figure 5 
Inhibition of Notch signaling promotes the differentiation of embryonic myogenic progenitors in vitro a. The mRNA levels of Notch genes in control (DMSO-treated) and DAPT-treated LR muscle progenitors cultured in GM for $3 \mathrm{~d}$. b. The protein levels of Notch genes in cells described as (A). c. The mRNA levels of Pax7 and MyoD in control and DAPT-treated cells cultured in GM for $3 \mathrm{~d}$. d. The protein levels of Pax7 and MyoD in cells described as (C). e. Immunofluorescent staining for MyoD in control and DAPT-treated muscle progenitors cultured in GM for indicated times. Scale bar $=100 \mu \mathrm{m}$. f. Percentages of MyoDpositive cells in (e) were counted in six microscopic fields for each group. g. Immunofluorescent staining for eMyHC was performed in treated muscle progenitor cells at $6 \mathrm{~d}$ after differentiation induction. Scale bar $=200 \mu \mathrm{m}$. h. The fusion index of differentiated progenitor cells in (g) was calculated. I. Western blot detected the protein levels of eMyHC in cells described as $(\mathrm{g})$. Data are showed as mean $\pm \mathrm{SEM}, \mathrm{n}=6$ per group. ${ }^{\star} \mathrm{P}<.05,{ }^{\star \star} \mathrm{P}<.01,{ }^{\star \star \star} \mathrm{P}<0.001$ (Student's $\mathrm{t}$ test). 

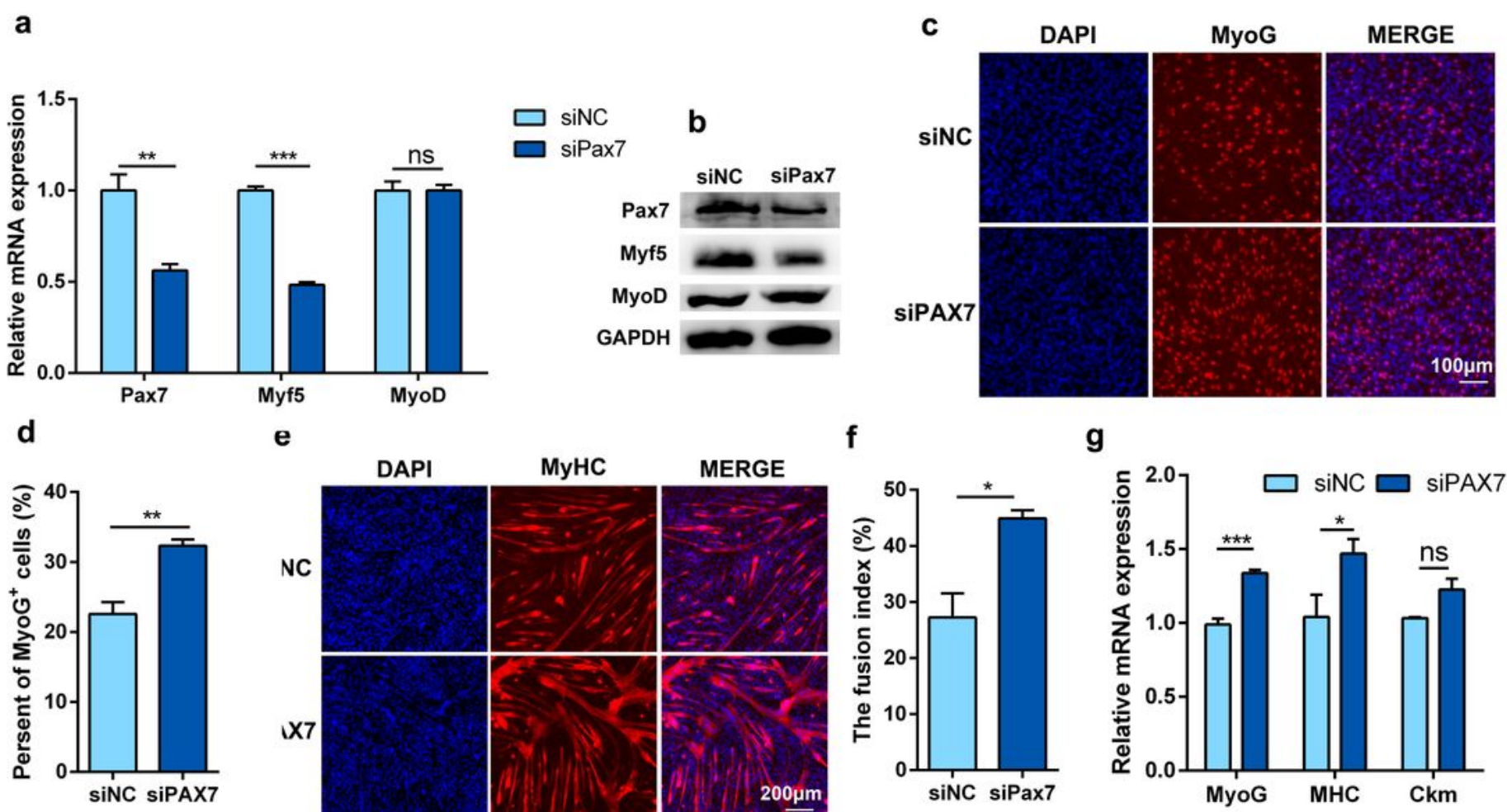

e

f
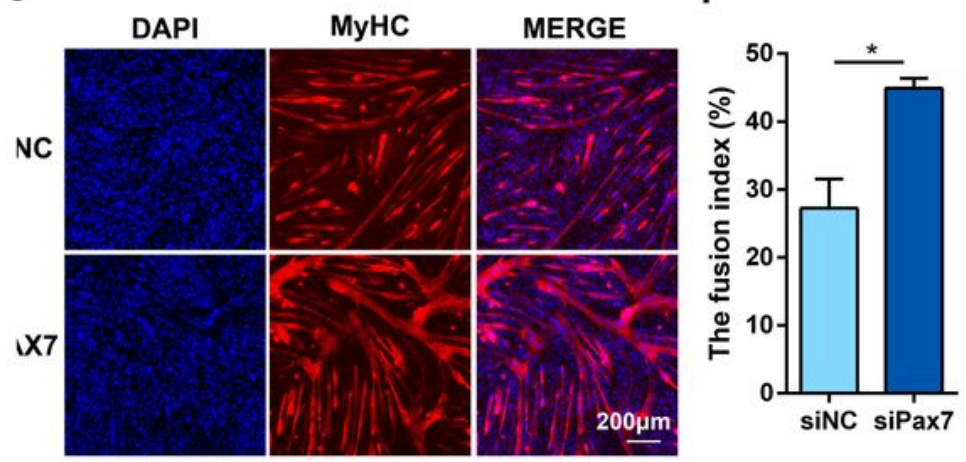

g

h

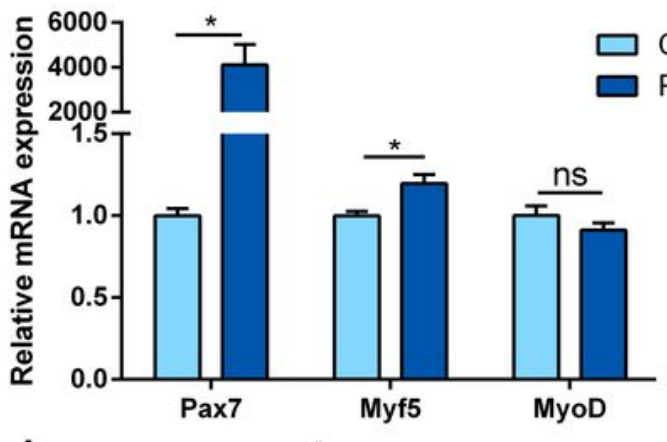

Control

Pax7
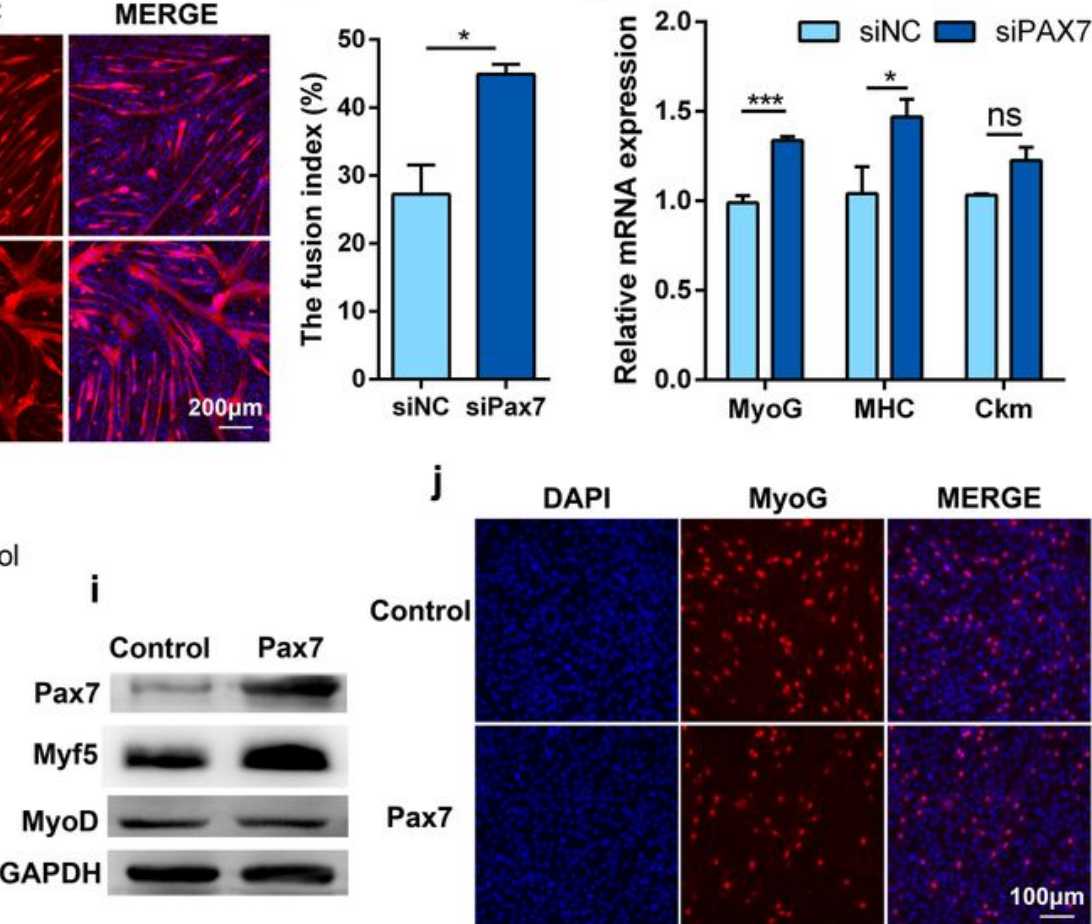

k

I
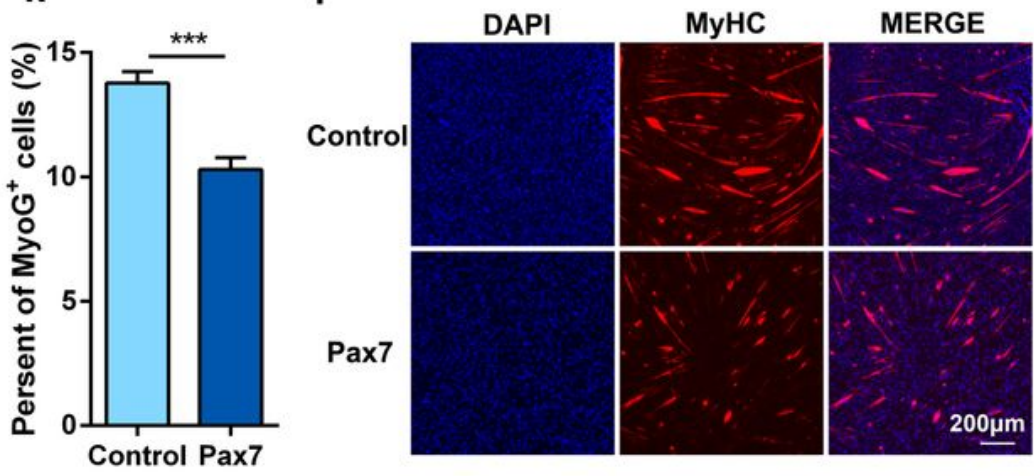

m

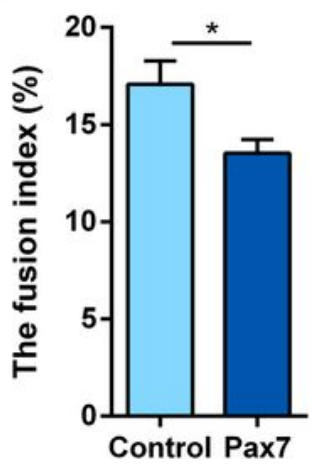

n

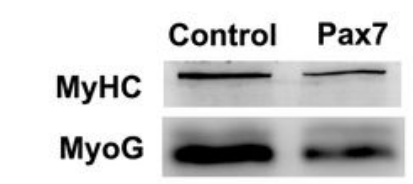

$\boldsymbol{\beta}$-tubulin

Figure 6

Pax7 inhibits terminal differentiation of myoblasts a-b. The mRNA and protein levels of Pax7, Myf5 and MyoD in cells transfected with Pax7 siRNA and cultured in GM. c. After transfection and differentiation for $1 \mathrm{~d}$, cell differentiation was detected by MyoG immunofluorescence staining. Scale bar=100 $\mu \mathrm{m}$. $\mathrm{d}$. Percentages of MyoG-positive cells in (c) were counted in six microscopic fields for each group. e. Immunofluorescent staining for $\mathrm{MyHC}$ was performed in treated cells at $3 \mathrm{~d}$ after differentiation 


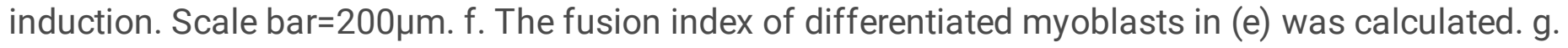
qPCR analysed the mRNA levels of myoblast differentiation markers. h-i. The mRNA and protein levels of Pax7, Myf5 and MyoD in cells transfected with pCDNA3.1-Pax7 and cultured in GM. j. Myoblast differentiation was detected by MyoG immunofluorescence staining after transfection and differentiation for $1 \mathrm{~d}$. Scale bar $=100 \mu \mathrm{m}$. k. Percentages of MyoG-positive cells in (j) were counted in six microscopic fields for each group. I. Immunofluorescent staining for MyHC was performed in treated cells at $3 \mathrm{~d}$ after differentiation induction. Scale bar $=200 \mu \mathrm{m}$. $\mathrm{m}$. The fusion index of differentiated myoblasts in (I) was calculated. $\mathrm{n}$. The protein levels of $\mathrm{MyHC}$ and $\mathrm{MyOG}$ in treated cells at $3 \mathrm{~d}$ after differentiation induction. Data are showed as mean \pm SEM, $n=6$ per group. ${ }^{\star} \mathrm{P}<.05,{ }^{\star \star} \mathrm{P}<.01,{ }^{\star \star \star} \mathrm{P}<0.001$ (Student's $\mathrm{t}$ test). 

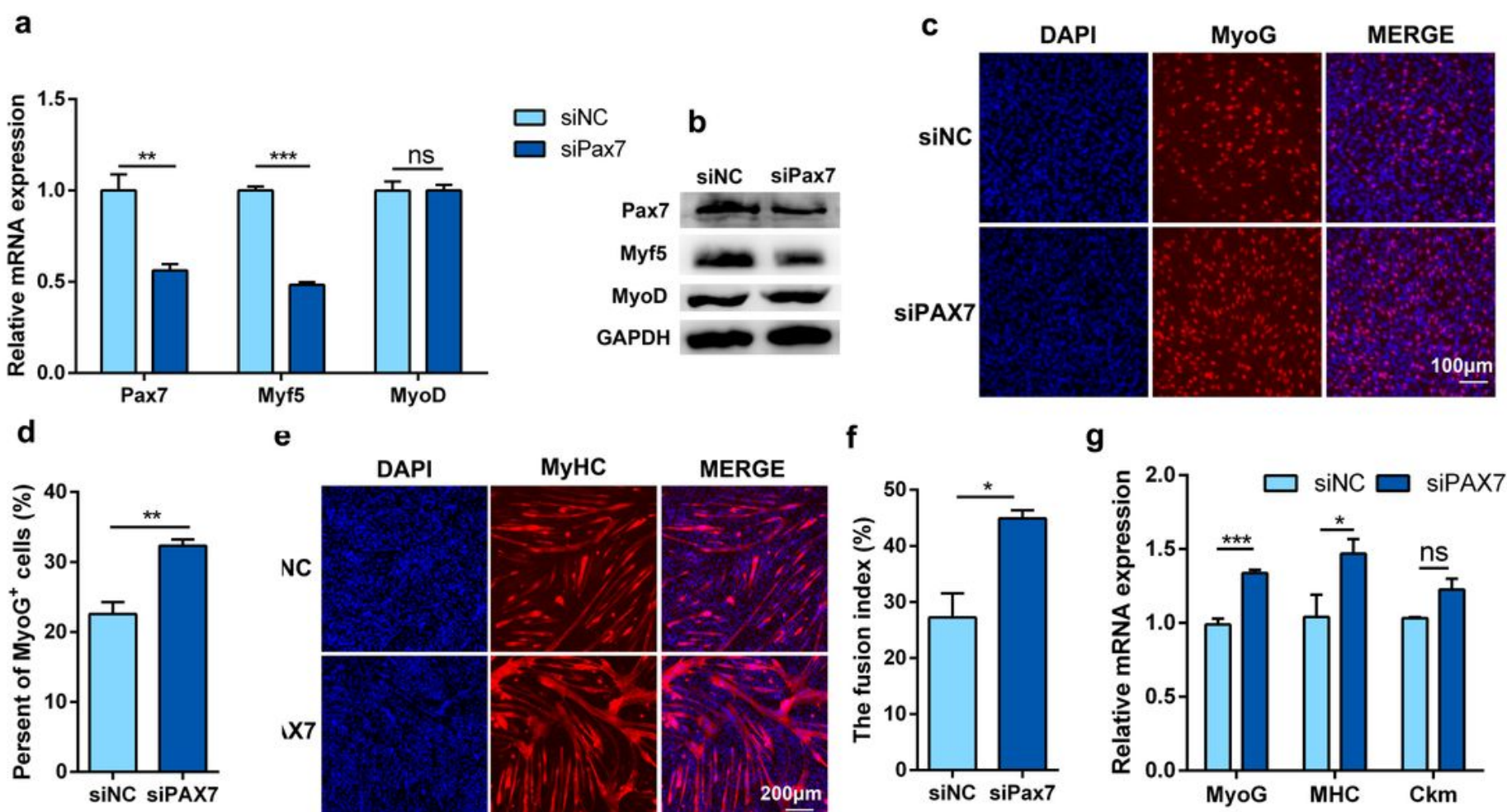

$\mathbf{e}$

f
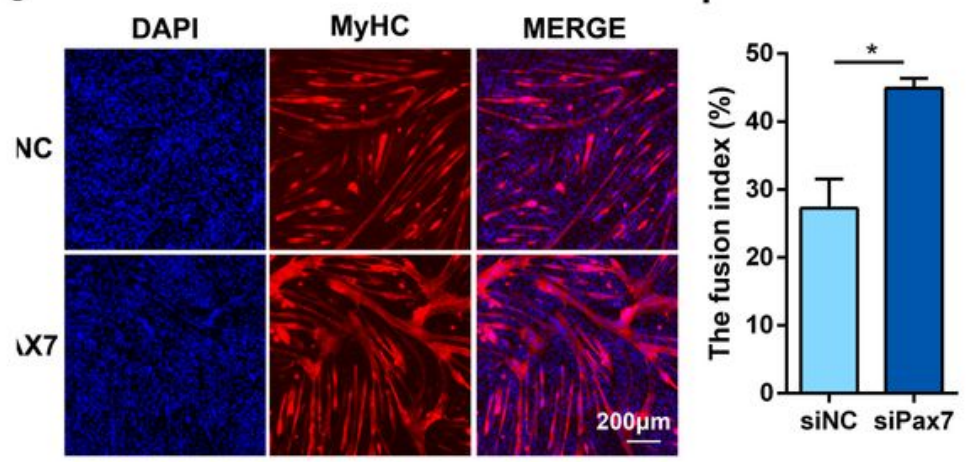

g

h

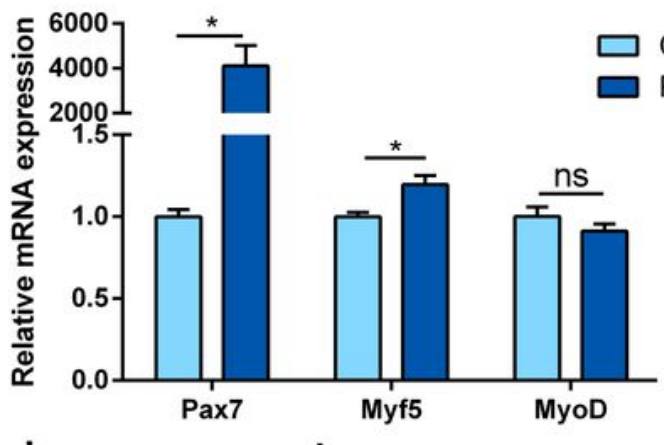

Control

Pax7

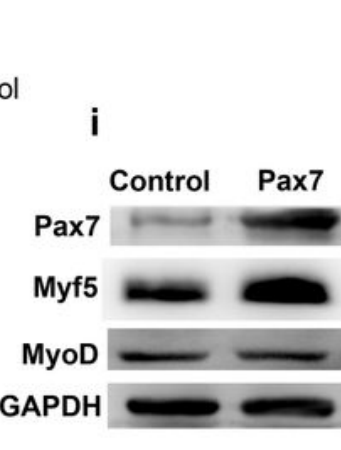

j

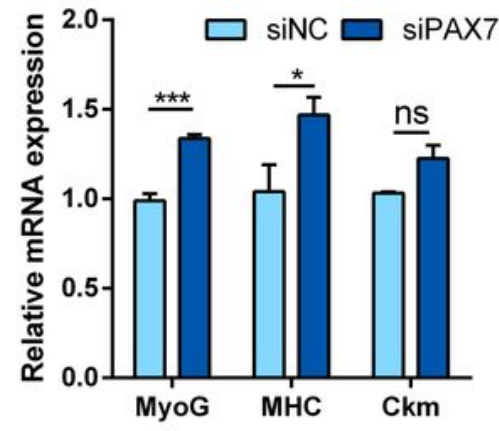

I
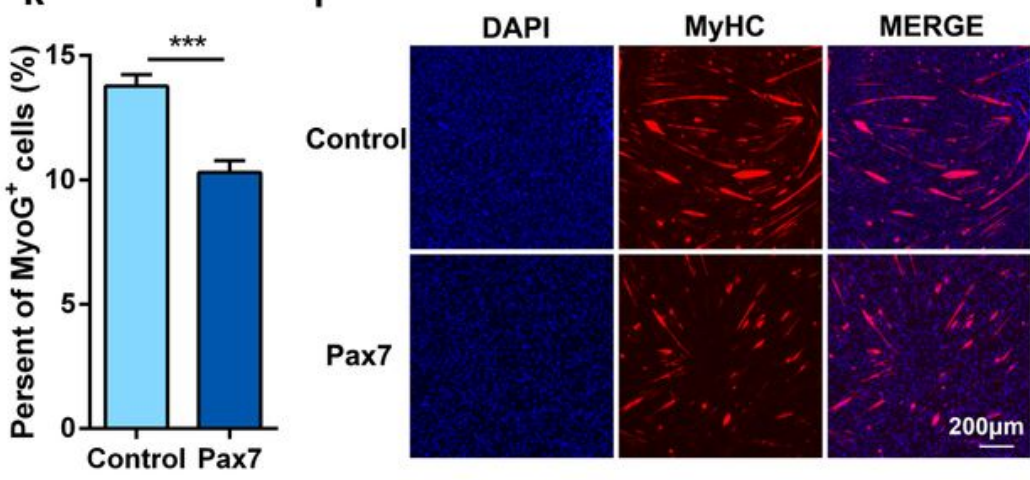

m

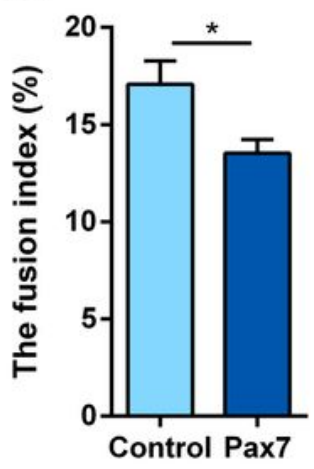

$\mathbf{n}$

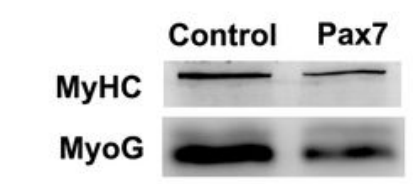

$\boldsymbol{\beta}$-tubulin

Figure 6

Pax7 inhibits terminal differentiation of myoblasts a-b. The mRNA and protein levels of Pax7, Myf5 and MyoD in cells transfected with Pax7 siRNA and cultured in GM. c. After transfection and differentiation for 1d, cell differentiation was detected by MyoG immunofluorescence staining. Scale bar=100 $\mu \mathrm{m}$. $\mathrm{d}$. Percentages of MyoG-positive cells in (c) were counted in six microscopic fields for each group. e. Immunofluorescent staining for $\mathrm{MyHC}$ was performed in treated cells at $3 \mathrm{~d}$ after differentiation 
induction. Scale bar=200 $\mu \mathrm{m}$. f. The fusion index of differentiated myoblasts in (e) was calculated. $\mathrm{g}$. qPCR analysed the mRNA levels of myoblast differentiation markers. h-i. The mRNA and protein levels of Pax7, Myf5 and MyoD in cells transfected with pCDNA3.1-Pax7 and cultured in GM. j. Myoblast differentiation was detected by MyoG immunofluorescence staining after transfection and differentiation for $1 \mathrm{~d}$. Scale bar $=100 \mu \mathrm{m}$. k. Percentages of MyoG-positive cells in (j) were counted in six microscopic fields for each group. I. Immunofluorescent staining for MyHC was performed in treated cells at $3 \mathrm{~d}$ after differentiation induction. Scale bar $=200 \mu \mathrm{m}$. $\mathrm{m}$. The fusion index of differentiated myoblasts in (I) was calculated. $n$. The protein levels of MyHC and MyoG in treated cells at $3 \mathrm{~d}$ after differentiation induction. Data are showed as mean \pm SEM, $n=6$ per group. ${ }^{*} \mathrm{P}<.05,{ }^{*} \mathrm{P}<.01,{ }^{* \star} \mathrm{P}<0.001$ (Student's $\mathrm{t}$ test).

a

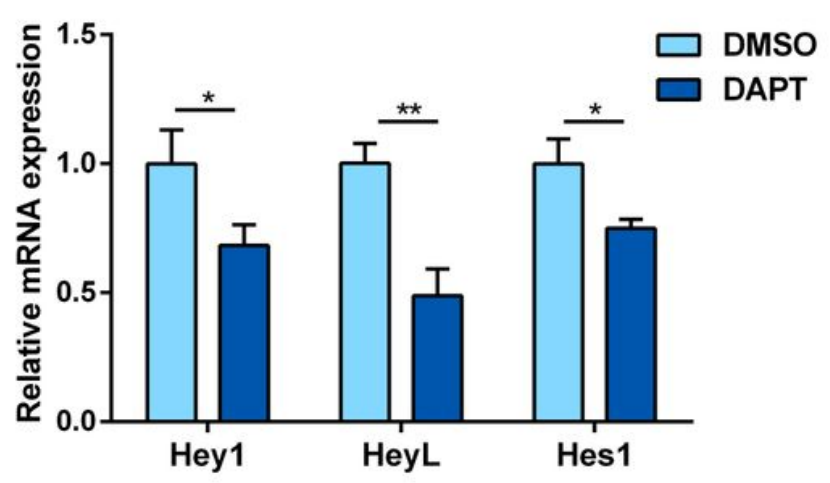

d

d Pax7

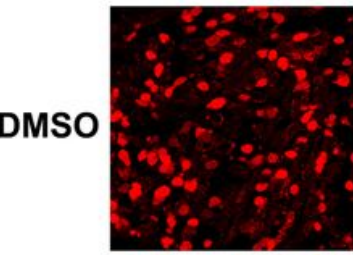

DAPT

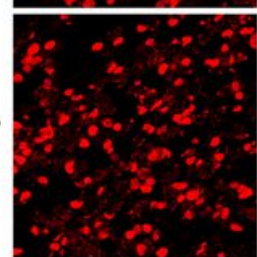

b

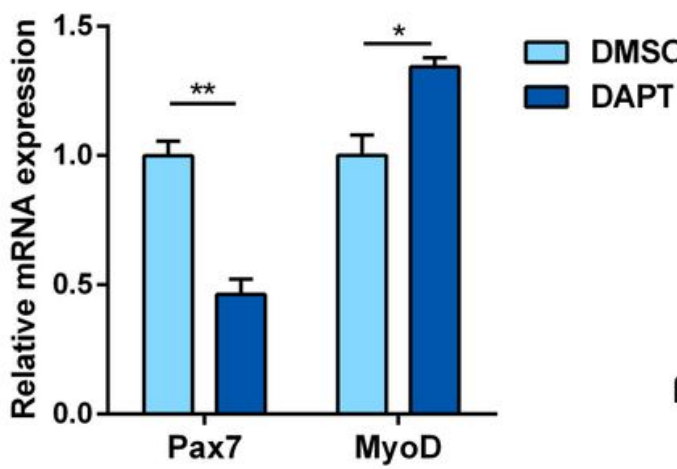

e

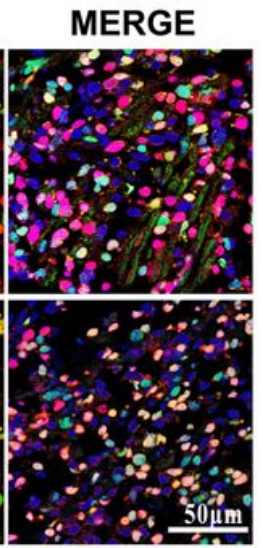

C

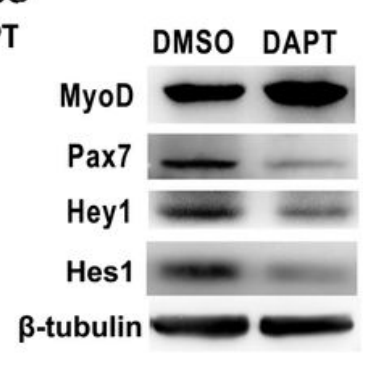

\section{Figure 7}

Notch signaling prevents myogenic differentiation of embryonic muscle progenitors a-b. qPCR results for Hey1, Hey L, Hes1, Pax7 and MyoD mRNA in control (DMSO-treated) and DAPT-treated ex vivo limb culture. c. The protein levels of Hey1, Hey L, Hes1, Pax7 and MyoD in ex vivo whole limb culture. d. Immunofluorescence staining for Pax7 and MyoD on cross sections of control and DAPT-treated limb explants from LR 35 dpc embryos. The cell nucleus was stained with DAPI (blue). Scale bar $=50 \mu \mathrm{m}$. e. Percentages of three cell populations (Pax7+/MyoD- progenitor cells, Pax7+/MyoD+ committed myoblasts and Pax7-/MyoD+ differentiated myoblasts) in (d) were counted in six microscopic fields for each group. 
a

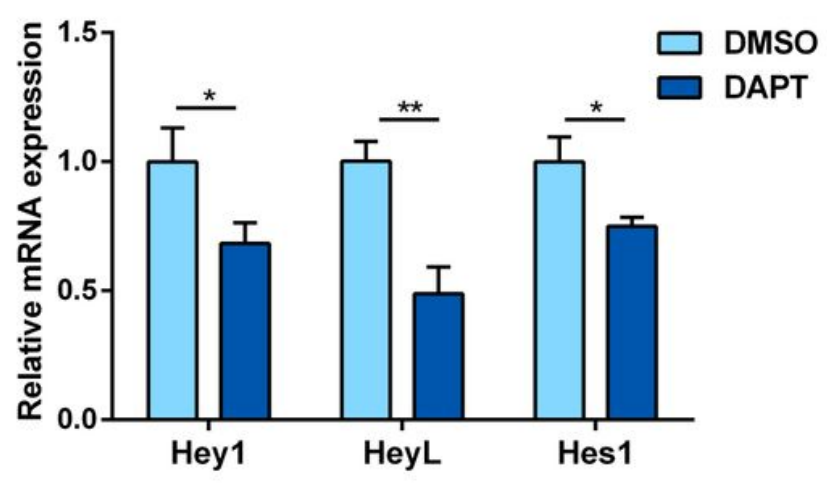

b

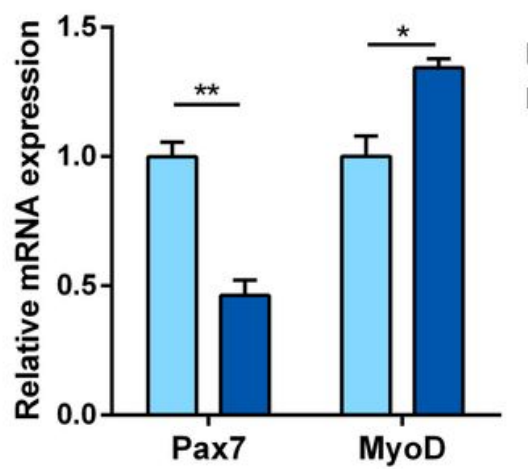

C

DMSO

DAPT

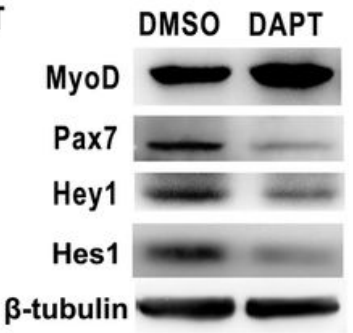

d

d $\quad \operatorname{Pax} 7$

MyoD

Pax7/MyoD

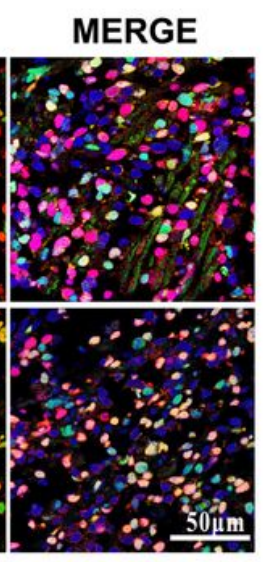

e

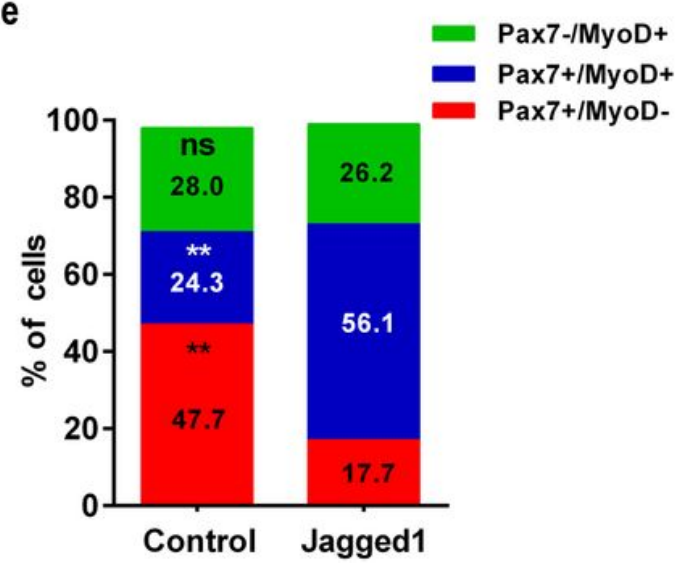

Figure 7

Notch signaling prevents myogenic differentiation of embryonic muscle progenitors a-b. qPCR results for Hey1, Hey L, Hes1, Pax7 and MyoD mRNA in control (DMSO-treated) and DAPT-treated ex vivo limb culture. c. The protein levels of Hey1, Hey L, Hes1, Pax7 and MyoD in ex vivo whole limb culture. d. Immunofluorescence staining for Pax7 and MyoD on cross sections of control and DAPT-treated limb explants from LR 35 dpc embryos. The cell nucleus was stained with DAPI (blue). Scale bar $=50 \mu \mathrm{m}$. e. Percentages of three cell populations (Pax7+/MyoD- progenitor cells, Pax7+/MyoD+ committed myoblasts and Pax7-/MyoD+ differentiated myoblasts) in (d) were counted in six microscopic fields for each group. 


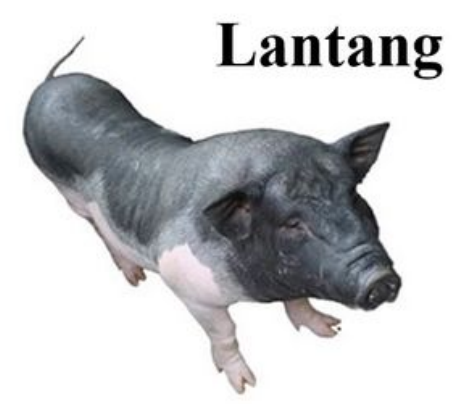

Landrace
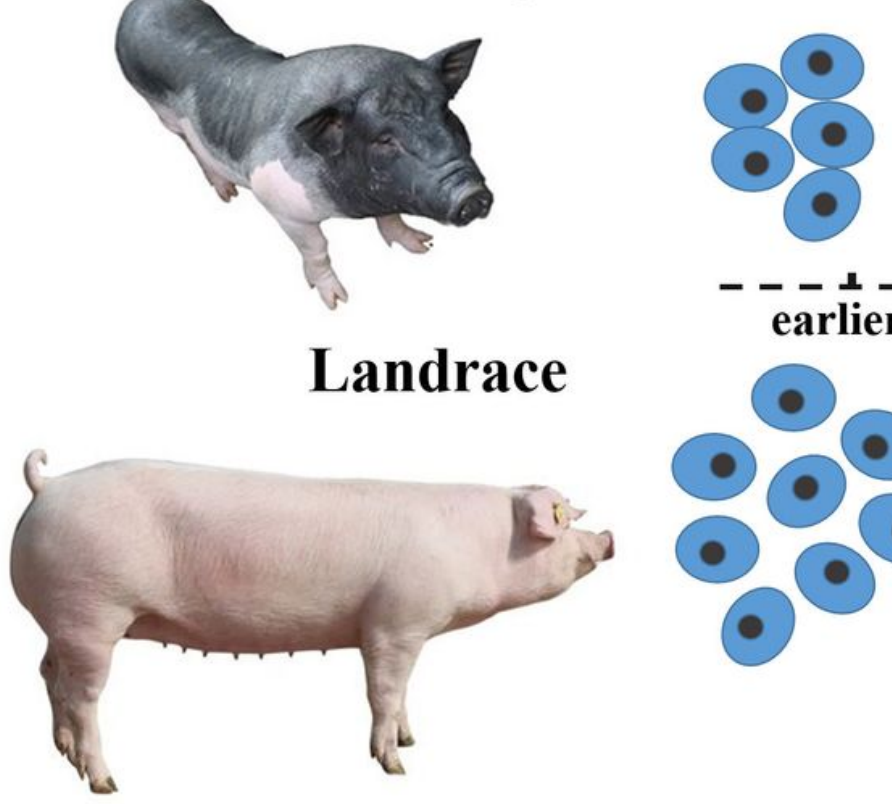
Weaker notch signals
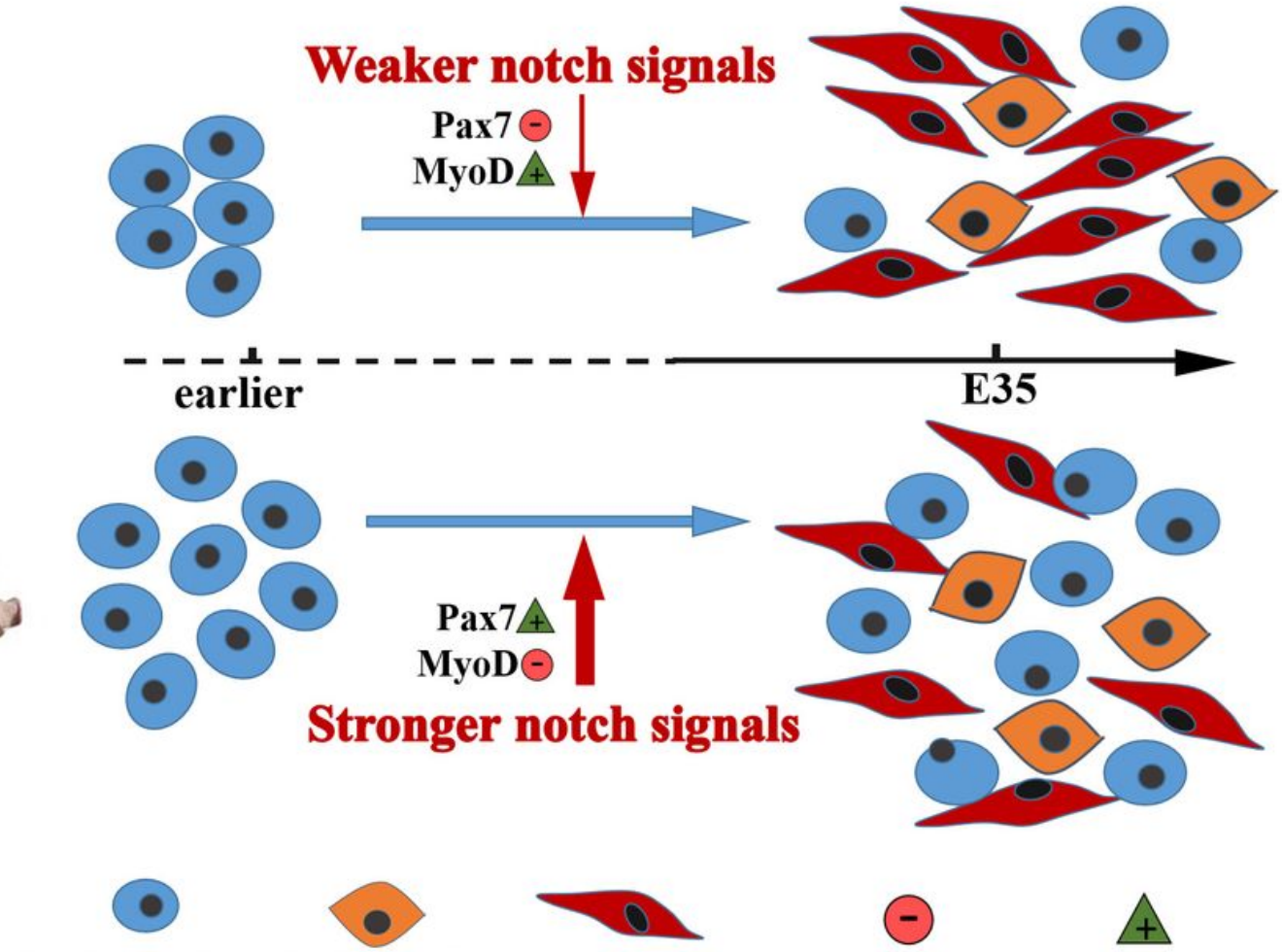

Pax7+/MyoD- Pax7+/MyoD+ cell cell
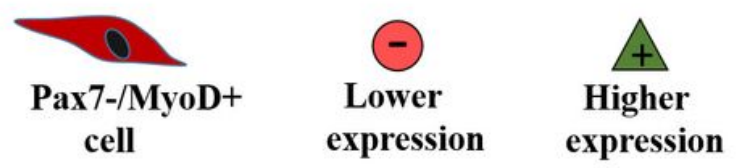

Figure 8

Schematic diagram of Notch signaling regulation on myogenic differentiation of LT and LR embryonic muscle progenitors 


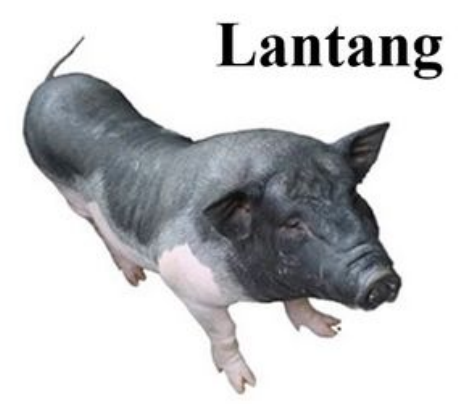

Landrace
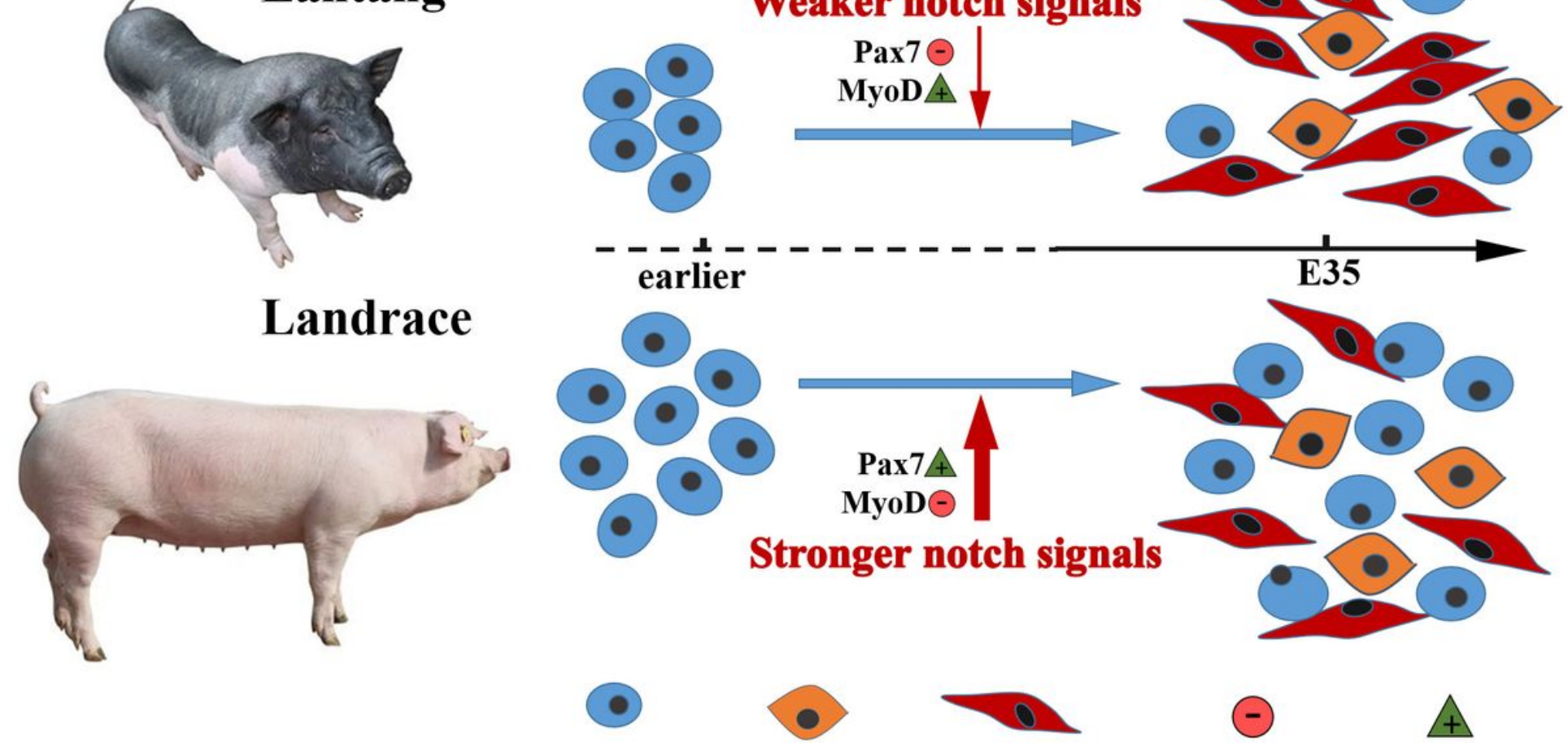

Pax7+/MyoD cell

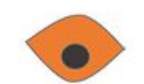

Pax7+/MyoD+ cell

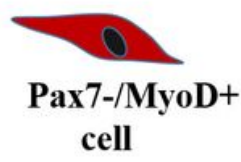

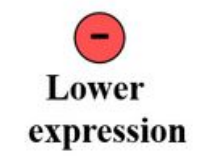

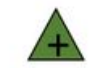

Higher expression

Figure 8

Schematic diagram of Notch signaling regulation on myogenic differentiation of LT and LR embryonic muscle progenitors

\section{Supplementary Files}

This is a list of supplementary files associated with this preprint. Click to download.

- sfig1.JPG

- sfig1.JPG 